\title{
ANÁLISIS DE FOTOLINEAMIENTOS DE LA REPUBLICA DOMINICANA
}

\author{
Sergio Chiesa ${ }^{1)}$, Giovanna Civelli ${ }^{2)} \&$ Simone de Toni ${ }^{2)}$ \\ 1) CNR - Centro di Studio per la Geodinamica Alpina e Quaternaria, Milano, Italia. \\ E-mail cnrbg@uninetcom.it \\ 2) GEOISA INTERNACIONAL S.A. - San José, Costa Rica. E-mail \\ geos@infoweb.co.cr
}

(Recibido 2/03/199; Aceptado 8/01/2001)

\begin{abstract}
With the aim of implementing an instrumental network for monitoring the micro-seismicity of the whole territory of the Dominican Republic, a remote sensing study was performed.

This study was based on georeferenced black/white images LANDSAT TM (Thematic Mapper) at a scale 1:250.000. The aim of the study was the recognition and analysis of lineaments of the entire territory of Dominican Republic. The term "lineament" corresponds to all linear elements, generally rectilinear or slightly curvilinear, that intersect topographic surface and are connected with geological phenomena that concern bedrock. All lineaments recognized (17.300 for a total lenght of $26.000 \mathrm{~km}$ ) were plotted on a map at a 1:500.000 scale. Furthermore, a statistic analysis of the lineament radial distribution and of their persistence was done. Lineaments recognized can be compared with bibliographic data and are compatible with cinematic models presently applied to explain the recent history of Dominican Republic.
\end{abstract}

RESUMEN: El objeto de este estudio es el análisis de lineamientos satelitales realizado en el ámbito del Proyecto D: Prevención de Riesgos Geológicos (Riesgos Sísmicos) del Programa de Desarrollo Geológico-Minero SYSMIN, hecho en el curso de los años 1998 y 1999 en colaboración entre la República Dominicana y la Comunidad Europea, que financió el Programa. Este Proyecto fue de especial importancia para sentar las bases científicas para una correcta prevención del riesgo sísmico en la República Dominicana.

Este análisis se ha desarrollado a partir de imágenes LANDSAT TM (Thematic Mapper), cubriendo por completo la superficie del territorio nacional de la República Dominicana. Las imágenes son de tipo georeferenciado, con ampliación en la escala 1:250 000, y corresponden a la banda de largo de onda 5, con restitución en tonos de gris (es decir, imágenes en blanco y negro).

El paso siguiente fue la elaboración de un mapa de los lineamientos a escala 1:500 000, donde se han representado todos los 17300 lineamientos detectados (para una longitud total de más de $26000 \mathrm{~km}$ ).

Además, se ha hecho un estudio estadístico sobre la distribución radial y la persistencia de los lineamientos reconocidos. La comparación de los resultados del análisis de distribución radial con datos y modelos de interpretación con base en la literatura publicada ha permitido reconocer que los lineamientos detectados tienen rumbos compatibles con el modelo cinemático actualmente aplicado para explicar la historia reciente (pleistocena) de la isla Española.

\section{MARCO ESTRUCTURAL Y MODELO CINEMÁTICO}

La República Dominicana, parte de la isla Española, está situada cerca del margen entre las placas de Norteamérica y Caribe, en una faja sismogénica dominada por movimientos transcurrentes izquierdos (Fig. 1).

A partir del conjunto de todos los datos conocidos en la literatura, el sector occidental de 
la isla Española está sujeto a un régimen tectónico de transpresión, conectado a un sistema de fallas transcurrentes izquierdas con rumbo variable entre E-W y ENE-WSW. Este modelo explica la cinemática de la mayoría de las estructuras recientes presentes en la isla, sea las ya conocidas en la literatura, sea las identificadas por medio de la interpretación de las imágenes satelitales.

Las estructuras principales (Fig. 2) presentan un rumbo variable entre E-W y N $100^{\circ}$ $110^{\circ}$ y son caracterizadas por movimiento lateral izquierdo (SFZ Septentrional fault zone, EPGFZ Enriquillo Plantain Garden fault zo$n e)$. Volviendo hacia la dirección WNW-ESE, las estructuras asumen componentes de movimiento contrario y se convierten en fallas transpresivas (BFZ Bonao fault zone, SJRFZ San José-Restauración fault zone, HFZ Hispañiola fault zone), originando fallas inversas de alto ángulo, pliegues y raramente sobrecorrimientos. Este régimen causa la reactivación de estructuras más antiguas, como es evidente en la Cordillera Central, donde los principales contactos entre complejos diferentes parecen ser parcialmente reactivados bajo el presente campo de esfuerzos.
Pliegues en échelon se encuentran a lo largo de las zonas de corte entre las grandes fallas transcurrentes e inversas (lago Enriquillo, valle del Cibao).

Los fenómenos de tectónica extensional parecen bastante limitados en la isla, pero ocasionalmente han sido reconocidas fallas distensivas NE-SW (Maimón graben, Bahía de Escocesa y Bahía de Ocoa-Beata Fault Zone), que son compatibles con el cuadro deformativo y cinemático reconocido. A los fenómenos de extensión presentes a lo largo de estructuras NE-SW van ligados los episodios de volcanismo reciente de edad plio-cuaternaria, tanto en la Cordillera Central como en el Valle de San Juan. Del análisis de la distribución de los centros eruptivos, se deduce su alineación a lo largo de estructuras NE-SW, que pueden ser atribuidas probablemente a fallas distensivas y grietas de tensión, a través de las cuales los magmas subieron a la superficie. En la Cordillera Central estas estructuras parecen interrumpir también los frentes de cabalgamiento WNW-ESE.

En cuanto a las estructuras N-S, estas parecen estar presentes en la mayoría de la isla. Se trata de fallas transcurrentes dextrales secundarias

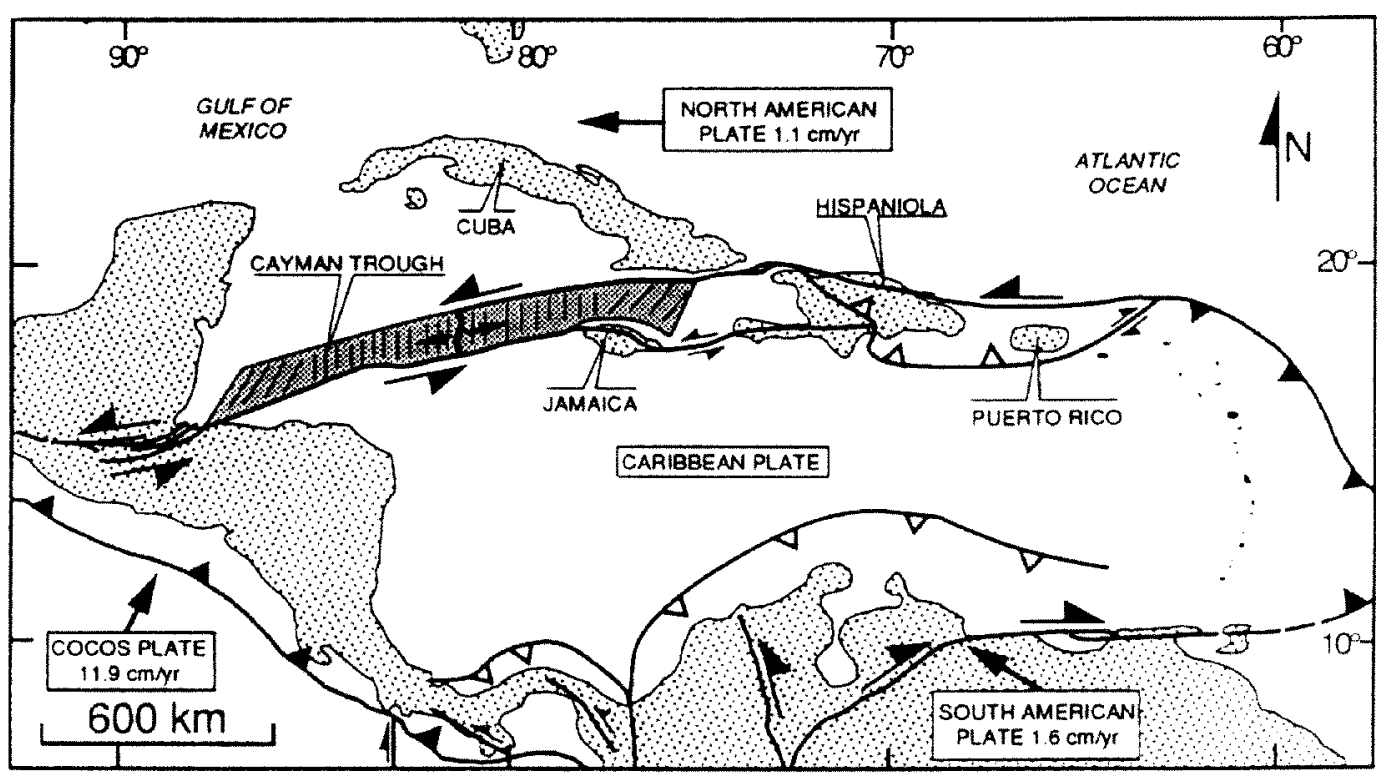

Fig. 1: Esquema de la geodinámica de la región caribeña (Mann et al., 1991) 


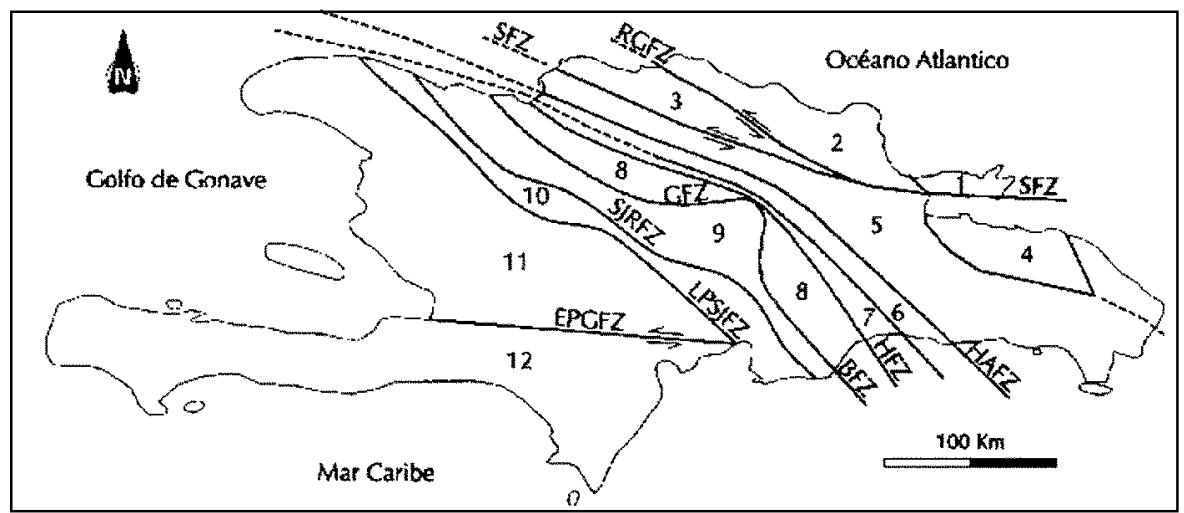

Fig. 2: Mapa esquemático de los "terrenos tectónicos" y de las zona de fallas en la isla Española (Mann et al., 1991). Leyenda de los "terrenos tectónicos": 1) Samaná; 2) Puerto Plata-Pedro García-Río San Juan; 3) Altamira; 4) Oro; 5) Seibo; 6) Tortue-Maimon-Amina; 7) Loma Caribe-Tavera; 8) Duarte; 9) Tireo; 10) Trois Riviéres-Peralta; 11) Presq'ile du Nord-Ouest-Neiba; 12) Hotte-Salle-Bahoruco.

Leyenda de las zona de fallas (ZF): BFZ: ZF Bonao; EPGFZ: ZF Enriquillo-Plantain Garden; GFZ: ZF Guacara; HAFZ: ZF Hatillo; HFZ: ZF Hispañiola; LPSJFZ: FZ Los Pozos-San Juan; RGFZ: FZ Río Grande; SFZ: FZ Septentrional; SJRFZ: FZ San José-Restauración.

(Riedel antitéticos: R1). Una importante faja de estas estructuras cruza el lado oriental de la bahía de Ocoa, y penetra en profundidad en la Cordillera Central. Esta faja coincide con la terminación del prisma de acreción de Los Muertos y la faja de contacto e indentación entre el Beata Ridge y los complejos del Río Ocoa y Peralta. La faja de cizalles parece además continuar en una zona de transpresión derecha de rumbo igual. Se trata en este caso de una estructura desvinculante (lateral ramp) de gran importancia.

La principal falta de homogeneidad con respecto de este modelo cinemático parece estar presente en el sector más oriental de la isla (Llano Costero Oriental y Cordillera Oriental), en donde los mapas indican la presencia de estructuras de distensión ESE-WNW que no son fácilmente explicables con el modelo considerado. Es todavía posible que en este sector el campo de esfuerzos sea parcialmente modificado por la presencia del prisma de acreción de Los Muertos.

En cuanto a los datos sismológicos, la mayor parte de la informacion relativa a la sismicidad superficial (sin comprender la actividad del prisma de Los Muertos) parece confirmar el cuadro cinemático presentado.

\section{METODOLOGÍA Y DESCRIPCIÓN DEL MAPA DE LINEAMIENTOS}

Como se ha señalado, el mapa de lineamientos (Fig. 8) incluye todos los lineamientos, en su gran mayoría fuertemente rectilíneos, que fueron individualizados y cartografiados.

Cabe recordar que lineamiento corresponde al término inglés lineament. En el sentido más amplio, lineamiento corresponde con todos los elementos lineales, en general aproximadamente rectilíneos o levemente curvilíneos, que intersecan a la superficie topográfica y están relacionados con fenómenos geológicos que afectan al substrato. Hay que observar que el estudio de imágenes de satélite permite destacar de manera clara todos los lineamientos debidos a la deformación de estilo rígido (frágil), especialmente cuando esta se manifiesta a través de dislocaciones con planos de fuerte buzamiento (lo que da lugar a lineamientos prácticamente rectilíneos). Por el contrario, deformaciones de estilo plástico (dúctil), así como, en general las representadas por dislocaciones de bajo ángulo (fallas inversas), resultan menos evidentes. Un último caso corresponde a las formas circulares, de tamaño mediano 
a grande, generalmente relacionadas con fenómenos volcánicos, volcano-tectónicos o magmáticos (como emplazamientos de cuerpos intrusivos). Dichas formas no fueron localizadas en el presente estudio, aunque resulta necesario indicar que éstas no representan un objeto de interés específico, y que, en ese caso, habría que escoger imágenes de diferentes combinaciones de bandas, que permitan su fácil individualización.

Como se ha mencionado, los lineamientos individualizados son en su mayoría prácticamente rectilíneos, sólo en algunos casos levemente curvilíneos; su longitud puede alcanzar los 2-3 $\mathrm{km}$, llegando raramente hasta los 4-5 km, mientras el valor promedio queda entre 1 y $2 \mathrm{~km}$.

Con respecto a la distribución espacial de los lineamientos, ésta resulta claramente heterogénea, exhibiendo densidades diferentes, según su pertenencia a diferentes "terrenos tectónicos" y su proximidad, o ubicación a lo largo de importantes elementos tectónicos, es decir zonas de falla (fault zones). Cabe señalar que, de acuerdo con Howell et al. (1985) y Mann et al. (1991), definimos un "terreno tectónico" como sigue: " $A$ tectonostratigraphic terreno is a fault-bounded package of rocks of regional extent characterized by geologic history which differs from that of neighboring terrenos. Terrenos may be characterized internally by a distinctive stratigraphy, but in some cases a metamorphic or tectonic overprint is the most distinctive characteristic.... In general, the basic characteristic of terrenos is that the present spatial relations are not compatible with the inferred geologic histories..."

En el mapa de lineamientos (Fig. 3), las mencionadas zonas de falla resultan subrayadas por unas fajas alargadas y muy angostas de densidad extremadamente elevada de lineamientos. Se destaca, por ejemplo, la perfecta correspondencia que se observa en el caso de la GFZ o Guacara Fault Zone (prominente además por el diseño característico del retículo hidrográfico, en los sectores de río Guacara, Sierra Atravesada y cuenca superior del río Yaque del Norte), y la faja de lineamientos detectados.

Cada elemento tectónico mayor, descrito como fault zone, resulta en realidad formado por un conjunto de elementos menores, parcialmente sustitutivos, acompañado por un campo de fracturas que sigue prácticamente todo el desarrollo lineal de la zona de falla y cuyo ancho está relacionado con las características mecánicas del macizo rocoso atravezado. Cabe observar que la presencia de numerosos elementos menores corresponde con un fenómeno típico de todas las deformaciones caracterizadas por una fuerte componente de rumbo (shear zones, con componentes transpresivos y transtensionales), como es el caso de la tectónica de la Isla Española y sus alrededores. Debido a esto, prácticamente no se observan diseños sencillos de lineamientos, que resulten más continuos en su extensión lineal y que dibujen los principales rasgos estructurales del área de interés.

Como última observación, hay que tomar en cuenta las características muy diferentes de imágenes registradas en forma digital (como los LAND$S A T$ TM) y las registradas en forma analógica de placas fotográficas (por ejemplo, las de SPACE SHUTTLE, large format camera), igual que las clásicas fotografías aéreas. El primer tipo resulta más adecuado para las evaluaciones sintéticas, a diferencia del segundo, instrumento mejor para observaciones analíticas, en las que caben la exacta geometría así como la continuidad en su extensión lineal.

El conjunto de lineamientos individualizados fue digitalizado, a fin de realizar el consiguiente análisis estadístico. Los lineamientos quedan entonces repartidos en clases azimutales, ordenados en diagramas en rosa y agrupados según su pertenencia a los diferentes "terrenos tectónicos" (Fig. 3).

Desde el punto de vista estadístico, hay que observar como el valor promedio de densidad de los lineamientos detectados puede estar relacionado con factores locales, claramente no pertenecientes a la geología. El ejemplo más evidente corresponde al valle tectónico de la Hoya de Enriquillo, que, en las imágenes estudiadas, queda lamentablemente cubierto por un tupido conjunto de nubes, especialmente a lo largo de su margen meridional. Dicho margen representa la expresión morfológica de un importante sistema de fallas, que, debido a las razones indicadas, resultaron enmascaradas casi por completo.

Además, cabe señalar que algunos lineamientos corresponden de manera muy clara con 
fallas normales, en parte pertenecientes a diseños generales transtensionales, con planos muy empinados y con evidencia de bloques hundidos, esto netamente subrayado por la morfología de la superficie topográfica (diseño de las formas de relieve y retículo hidrográfico).

\section{ANALISIS ESTADÍSTICO: METODOLOGÍA}

De los lineamientos reconocidos en las imágenes de satélite, y presentados en el mapa de lineamientos se ha hecho un análisis estadístico de su distribución radial y de su persistencia (Fig. 3).

La distribución radial respecto al norte ha sido analizada por medio de diagramas de rosas. Desde un punto de vista teórico estos diagramas se construyen a partir del rumbo de los lineamientos; los datos se reparten dentro de clases azimutales de $10^{\circ}$ grados de ancho cada una. Entonces, en el caso de rumbos las clases son 18. El peso de cada clase se expresa como porcentaje del diámetro de la rosa y la clase más importante se compara al $100 \%$ del diámetro de la misma, mientras las otras clases se representan como porcentajes proporcionalmente más pequeños.

Cada diagrama está constituido de dos rosas. En la primera, a la izquierda, la distribución del rumbo de los lineamientos se analiza como frecuencia (es decir el número de lineamientos que entra en cada clase azimutal), mientras en la segunda, a la derecha, la misma se analiza como longitud total (es decir la suma de todas las longitudes de los lineamientos de cada clase). El valor de cada clase se define como porcentaje del número total o de la longitud total de todos los lineamientos analizados. Bajo cada rosa se indica el porcentaje de la clase más importante.

Cabe señalar que, cuando se leen diagramas de rosa así hechos, éstos tienden a exaltar mucho la importancia de la familia principal de los lineamientos, en detrimento del resto.

Desde un punto de vista práctico todos los cálculos se han hecho automáticamente por medio de computadora. El primer paso fue la digitalización de los lineamientos por medio del programa AutoCAD. Después, por medio de un programa es- crito en LSP (lenguaje de programación bajo AutoCAD), se han extraído las parejas de coordenadas $\mathrm{X}$ e Y de los extremos de cada lineamiento. Posteriormente, con un programa en Basic (Zanchi, 1990), por medio de simples funciones trigonométricas, se ha calculado el rumbo y la longitud de los lineamientos, distribución de los datos en clases, cálculo de los porcentajes y dibujo de los diagramas.

El análisis de la persistencia se ha hecho por medio de histogramas a partir de las coordenadas de los extremos de los lineamientos. A partir de aquí se ha calculado la longitud de cada línea. A continuación la distribución por frecuencia y por longitud total, dentro de 6 clases de persistencia: de 0 a $1 \mathrm{~km}$, de 1 a $2 \mathrm{~km}$, de 2 a $4 \mathrm{~km}$, de 4 a 8 km, de 8 a $16 \mathrm{~km}$ y de más de $16 \mathrm{~km}$. En los histogramas se presentan ambas componentes (frecuencia y longitud). Para hacer estos cálculos se ha utilizado un programa de hoja de cálculo (Excel), con el cual se han calculado también otros parámetros como son la longitud promedio y la densidad promedio de los lineamientos de cada terreno tectónico.

Es necesario señalar que en la discusión de los datos que sigue, el ángulo azimutal de los rumbos expresado en sentido horario a partir del norte (por ejemplo rumbo $\mathrm{N} 100^{\circ}$ significará rumbo $100^{\circ}$ desde norte hacia este).

\section{DISCUSIÓN DE LOS DATOS}

El área de estudio ha sido subdividida en 12 zonas homogéneas. Cada una de ellas corresponde a uno de los 12 "terrenos tectónicos" reconocidos por Mann et al. (1991) en la isla Española (Fig. 2).

Los lineamientos detectados por medio del análisis de las imágenes de satélite son 17303 para una longitud total de más de $26240 \mathrm{~km}$.

En la primera serie de diagramas se han considerado todos los datos encontrados dentro de cada "terreno tectónico" (Fig. 3). El resultado fue una fuerte uniformidad (Cuadro 1) en todos los diagramas, sea en las rosas de la frecuencia (izquierda) sea en aquellas de la longitud (derecha). Se obtuvo una única clase angular dominante, constituída por lineamientos de rumbo E$\mathrm{W}\left(\mathrm{de} \mathrm{N} 90^{\circ}\right.$ a $\mathrm{N} 100^{\circ}$ ). Solo en tres diagramas, 

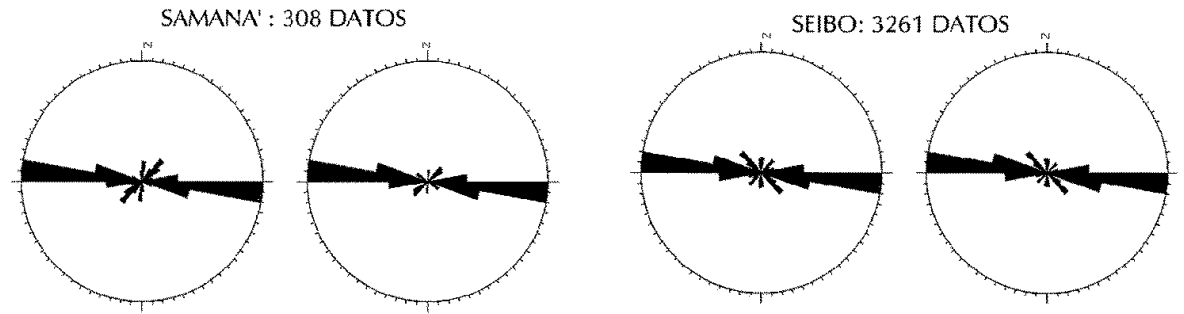

P.PLATA - P.GARCIA - R.S.JUAN : 848 DATOS
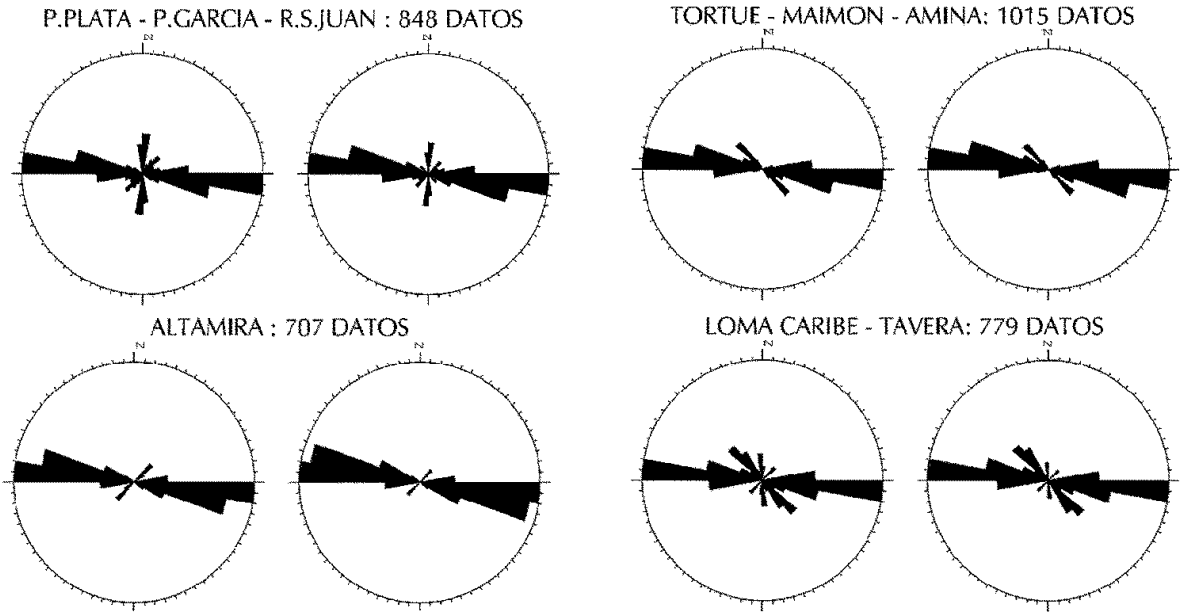

LOMA CARIBE - TAVERA: 779 DATOS
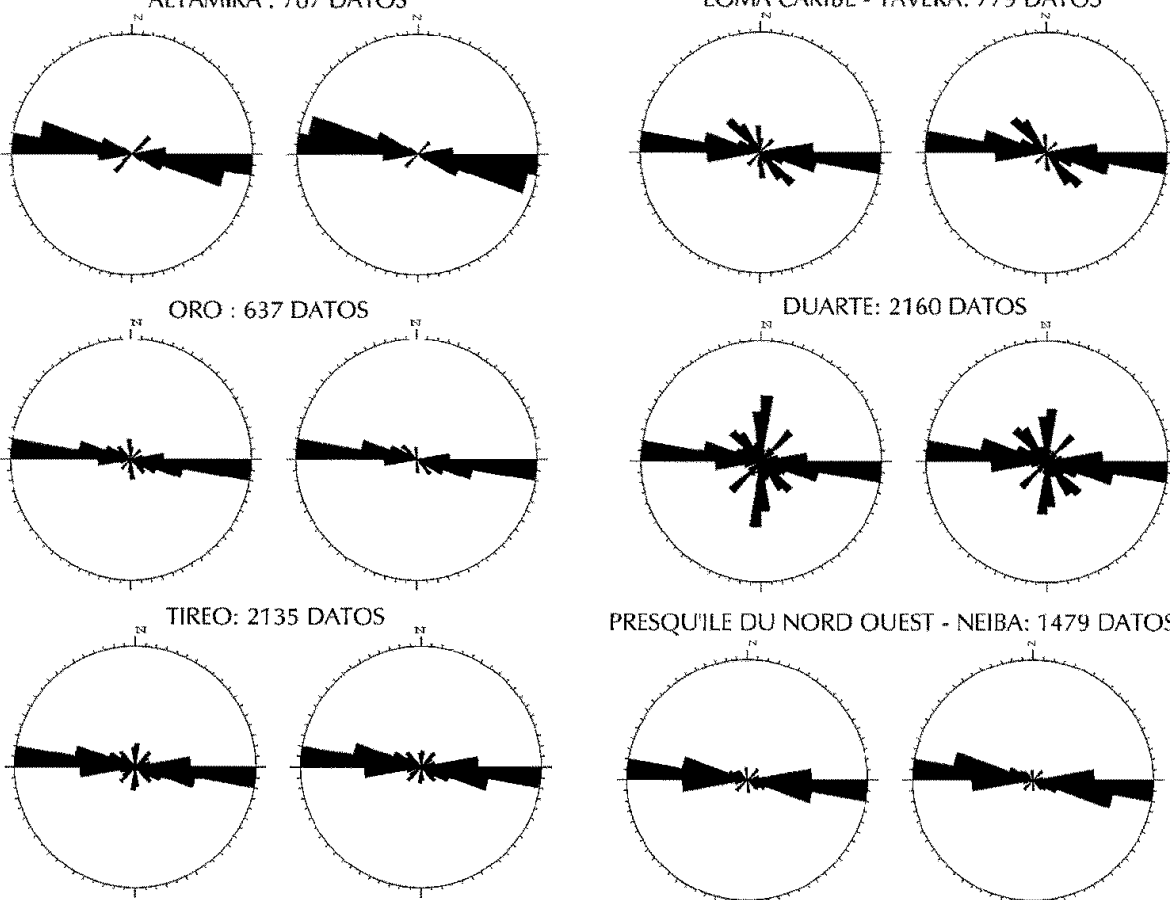

PRESQUILE DU NORD OUEST - NEIBA: 1479 DATOS
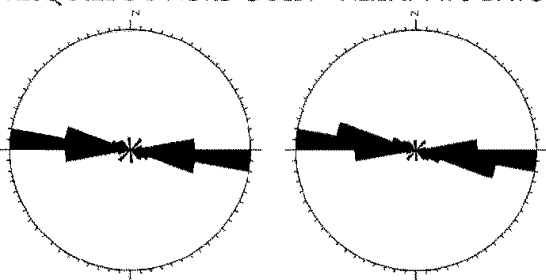

TROIS RIVIERES - PERALTA: 2441 DATOS
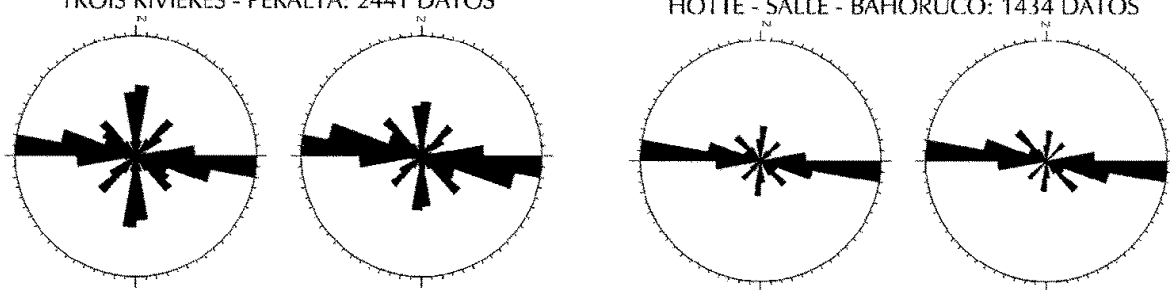

Fig. 3: Diagramas de todos los datos encontrados dentro de cada "terreno tectónico". Izquierda: rosa de frecuencia; derecha: rosa de longitud. 
Cuadro 1

Análisis estadístico, distribución radial, compendio de los rumbos principales de la totalidad de lineamientos

\begin{tabular}{|c|c|c|c|c|}
\hline Terreno Tectónico & \# datos & Rumbo principal & $\%$ Frecuencia & $\%$ Longitud \\
\hline Samaná & 308 & $\mathrm{~N} 90^{\circ}-100^{\circ}$ & 31,09 & 38,12 \\
\hline Pto Plata-Pedro García-río San Juan & 848 & $\mathrm{~N} 90^{\circ}-100^{\circ}$ & 26,53 & 27,85 \\
\hline Altamira & 707 & $\mathrm{~N} 90^{\circ}-100^{\circ}$ & 33,52 & 32,79 \\
\hline Oro & 637 & $\mathrm{~N} 90^{\circ}-100^{\circ}$ & 33,75 & 37,04 \\
\hline Seibo & 3261 & $\mathrm{~N} 90^{\circ}-100^{\circ}$ & 32,68 & 34,41 \\
\hline Tortue-Maimon-Amina & 1015 & $\mathrm{~N} 90^{\circ}-100^{\circ}$ & 30,83 & 31,16 \\
\hline Loma Caribe-Tavera & 779 & $\mathrm{~N} 90^{\circ}-100^{\circ}$ & 26,82 & 27,86 \\
\hline Duarte & 2160 & $\mathrm{~N} 90^{\circ}-100^{\circ}$ & 19,56 & 19,83 \\
\hline Tireo & 2135 & $\mathrm{~N} 90^{\circ}-100^{\circ}$ & 27,29 & 28,75 \\
\hline Trois Riviéres-Peralta & 2441 & $\mathrm{~N} 90^{\circ}-100^{\circ}$ & 17,54 & 18,67 \\
\hline Presqu'Ile du Nord Ouest-Neiba & 1479 & $\mathrm{~N} 90^{\circ}-100^{\circ}$ & 31,37 & 31,66 \\
\hline Hotte-Salle-Bahoruco & 1533 & $\mathrm{~N} 90^{\circ}-100^{\circ}$ & 25,50 & 24,51 \\
\hline Depósitos Cuaternarios & 4233 & $\mathrm{~N} 90^{\circ}-100^{\circ}$ & 32,22 & 43,84 \\
\hline
\end{tabular}

Duarte, Trois Riviéres - Peralta y secundariamente en puerto Plata - Pedro García - río San Juan, se observa la presencia de lineamientos N$\mathrm{S}$ y sólo en los dos primeros se observan lineamientos NW-SE y NE-SW. En los otros diagramas casi no se observa ningún otro rumbo significativo.

Este marco E-W no coincide grandemente con los rumbos de las líneas tectónicas principales de la isla. En efecto, solamente la falla denominada EPGFZ y la parte oriental de la SFZ presentan una tendencia E-W, mientras que la mayoría de las otras presentan rumbos más o menos NW-SE.

Por esta razón, se han realizado también otras dos series de diagramas en rosas. En la primera se eliminaron todos los lineamientos de longitud menor de $2 \mathrm{~km}$ y en la segunda los de longitud menor de $4 \mathrm{~km}$.

El objetivo de estos otros análisis fue reducir el peso estadístico de los lineamientos más pequeños. En los cuadros 2 y 3 se presentan en síntesis las características de estos diagramas.

En el caso de las rosas de los datos mayores de $2 \mathrm{~km}$ (Fig. 4) se puede observar (Cuadro 2) que el efecto de esta "limpieza" fue una reducción parcial de la importancia de los lineamien- tos E-W a favor, sobretodo, de los lineamientos con rumbo N-S $\left(\mathrm{N}^{\circ}{ }^{\circ}-10^{\circ}, \mathrm{N} 160^{\circ}-170^{\circ}\right.$ y $\mathrm{N} 170^{\circ}$ $180^{\circ}$ ). Además, en 4 terrenos tectónicos (Seibo, Loma Caribe - Tavera, Duarte y Tireo) el rumbo principal por frecuencia de datos no corresponde al rumbo más importante obtenido para la longitud total.

Los diagramas hechos eliminando los lineamientos menores de $4 \mathrm{~km}$ (Fig. 5) presentan una geometría todavía más articulada con familias de lineamientos E-W, N-S, WNW-ESE, NWSE y NE-SW. En general estos diagramas tienen muchos menos datos que los de las otras dos series; por tanto, existe el riesgo de que sean menos representativos con respecto a los rumbos principales. En algunos casos, en efecto, los rumbos están bastante dispersos.

En una fase posterior del estudio se ha construído una última serie de diagramas de rosas, considerando solo los lineamientos que cruzaban depósitos cuaternarios (no presentes en este artículo).

El objetivo de esta parte del análisis era reconstuir las características de los lineamientos más recientes (estimados como más recientes porque afectan las unidades geológicas cuaternarias) y compararlas con las de los otros lineamientos, para poder evaluar si el conjunto de 

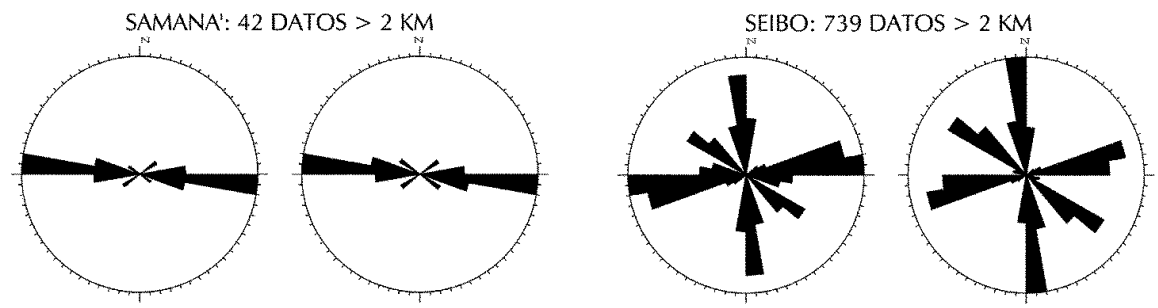

P.PLATA - P.GARCIA - R.S.JUAN: 212 DATOS $>2$ KM

TORTUE - MAIMON - AMINA: 300 DATOS $>2 \mathrm{KM}$
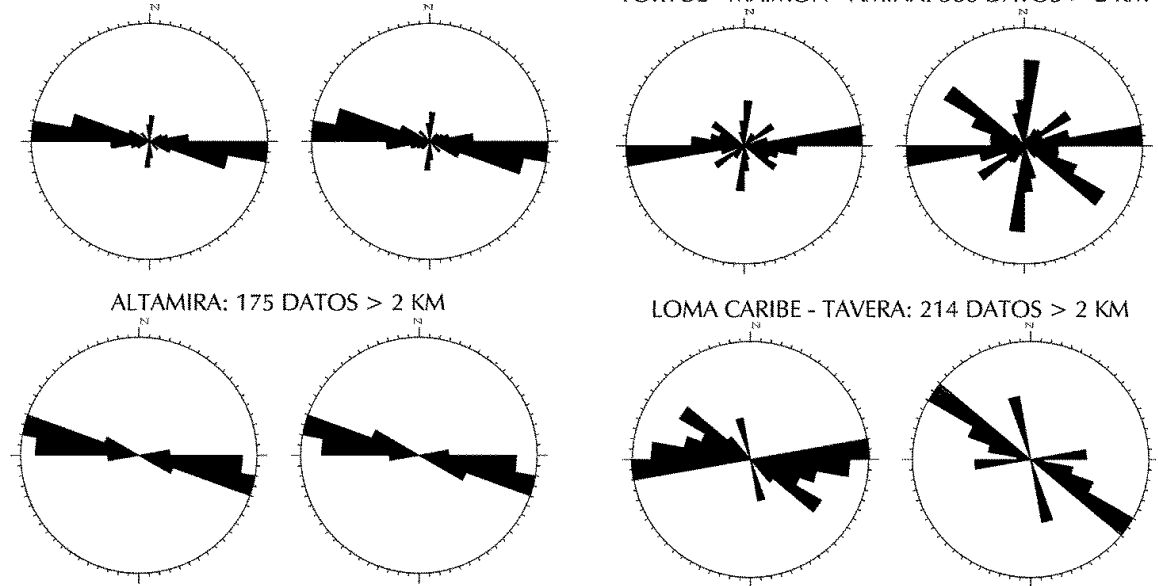

LOMA CARIBE - TAVERA: 214 DATOS $>2 \mathrm{KM}$
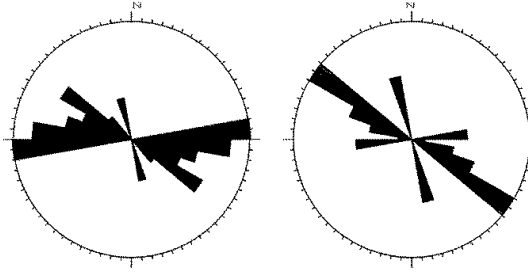

ORO: 147 DATOS > $2 \mathrm{KM}$
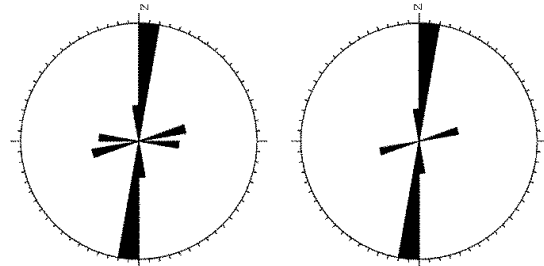

DUARTE: 499 DATOS $>2 \mathrm{KM}$
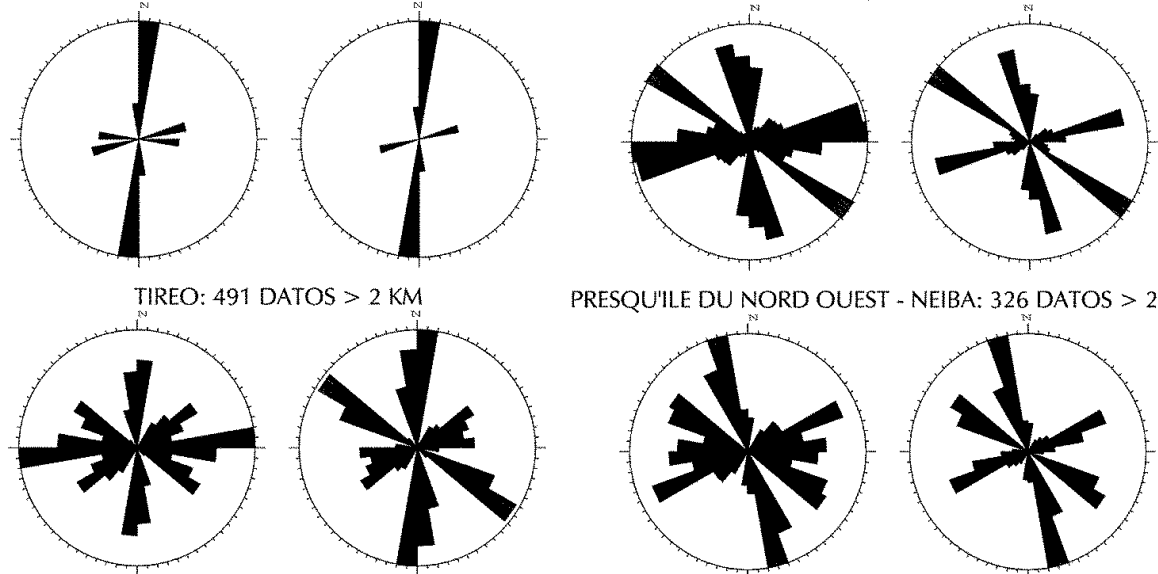

PRESQU'ILE DU NORD OUEST - NEIBA: 326 DATOS $>2$
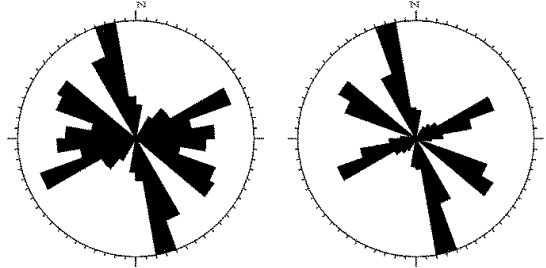

TROIS RIVIERES - PERALTA: 444 DATOS $>2 \mathrm{KM}$

HOTTE - SALLE - BAHORUCO: 341 DATOS $>2$ KM
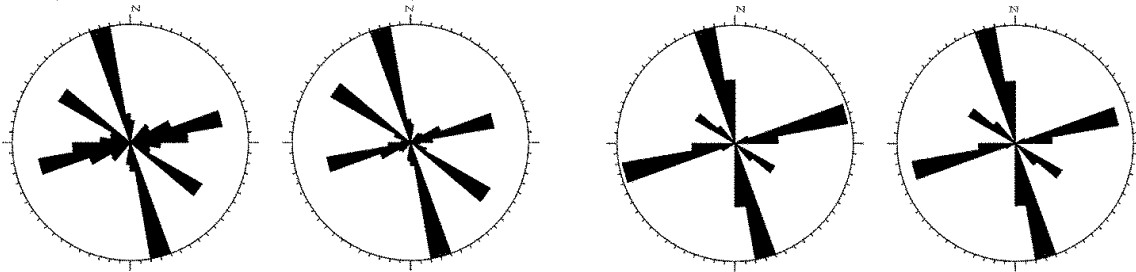

Fig. 4: Diagramas de las rosas de los datos mayores de $2 \mathrm{~km}$. Izquierda: rosa de frecuencia; derecha: rosa de longitud. 
Cuadro 2

Análisis estadístico, distribución radial, compendio de los rumbos principales. Lineamientos con longitud mayor de $2 \mathrm{~km}$

\begin{tabular}{|c|c|c|c|c|}
\hline Terreno tectónico & \# datos & Rumbo principal & $\%$ Frecuencia & $\%$ Longitud \\
\hline Samaná & 42 & $\mathrm{~N} 90^{\circ}-100^{\circ}$ & 42,85 & 41,34 \\
\hline Pto. Plata-Pedro García-río San Juan & 212 & $\mathrm{~N} 90^{\circ}-100^{\circ}$ & 30,10 & 26,88 \\
\hline Altamira & 176 & $\mathrm{~N} 100^{\circ}-110^{\circ}$ & 36,93 & 36,35 \\
\hline Oro & 147 & $\mathrm{~N} 0^{\circ}-10^{\circ}$ & 42,17 & 57,99 \\
\hline Seibo & 739 & $\mathrm{~N} 80^{\circ}-90^{\circ} ; \mathrm{N} 170^{\circ}-180^{\circ}$ & 17,18 & 18,75 \\
\hline Tortue-Maimon-Amina & 300 & $\mathrm{~N} 80^{\circ}-90^{\circ}$ & 25,33 & 17,23 \\
\hline Loma Caribe-Tavera & 214 & $\mathrm{~N} 80^{\circ}-90^{\circ} ; \mathrm{N} 120^{\circ}-130^{\circ}$ & 22,24 & 31,48 \\
\hline Duarte & 499 & $\mathrm{~N} 80^{\circ}-90^{\circ} ; \mathrm{N} 120^{\circ}-130^{\circ}$ & 12,42 & 20,19 \\
\hline Tireo & 491 & $\mathrm{~N} 0^{\circ}-10^{\circ} ; \mathrm{N} 80^{\circ}-90^{\circ}$ & 14,25 & 14,76 \\
\hline Trois Riviéres-Peralta & 444 & $\mathrm{~N} 160^{\circ}-170^{\circ}$ & 20,27 & 25,53 \\
\hline Presqu'Ile du Nord Ouest-Neiba & 326 & $\mathrm{~N} 160^{\circ}-170^{\circ}$ & 12,88 & 18,06 \\
\hline Hotte-Salle-Bahoruco & 413 & $\mathrm{~N} 90^{\circ}-100^{\circ}$ & 25,67 & 23,27 \\
\hline Depósitos Cuaternarios & 1136 & $\mathrm{~N} 80^{\circ}-90^{\circ} ; \mathrm{N} 170^{\circ}-180^{\circ}$ & 14,17 & 13,56 \\
\hline
\end{tabular}

Cuadro 3

Análisis estadístico, distribución radial, compendio de los rumbos principales. Lineamientos con longitud mayor de $4 \mathrm{~km}$

\begin{tabular}{lcccc}
\hline Terreno Tectónico & \# datos & Rumbo principal & \% Frecuencia & \% Longitud \\
\hline Samaná & 6 & $\mathrm{~N} 100^{\circ}-110^{\circ}$ & 50 & 42,01 \\
Pto. Plata-Pedro García-río San Juan & 49 & $\mathrm{~N} 100^{\circ}-110^{\circ}$ & 30,61 & 29,59 \\
Altamira & 37 & $\mathrm{~N} 90^{\circ}-100^{\circ}$ & 29,72 & 30,28 \\
Oro & 25 & $\mathrm{~N} 160^{\circ}-180^{\circ}$ & 40 & 35,53 \\
Seibo & 141 & $\mathrm{~N} 80^{\circ}-90^{\circ}$ & 19,14 & 25,68 \\
Tortue-Maimon-Amina & 63 & $\mathrm{~N} 110^{\circ}-120^{\circ}$ & 22,22 & 26,97 \\
Loma Caribe-Tavera & 43 & $\mathrm{~N} 60^{\circ}-70^{\circ}$ & 13,95 & 18,06 \\
Duarte & 102 & $\mathrm{~N} 70^{\circ}-80^{\circ}$ & 17,64 & 21,78 \\
Tireo & 79 & $\mathrm{~N} 170^{\circ}-180^{\circ}$ & 16,45 & 27,16 \\
Trois Riviéres-Peralta & 65 & $\mathrm{~N} 80^{\circ}-90^{\circ}$ & 20 & 22,26 \\
Presqu'Ile du Nord Ouest-Neiba & 45 & $\mathrm{~N} 90^{\circ}-100^{\circ} ; \mathrm{N} 100^{\circ}-110^{\circ}$ & 11,11 & 17,58 \\
Hotte-Salle-Bahoruco & 63 & $\mathrm{~N} 130^{\circ}-140^{\circ}$ & 15,87 & 16,54 \\
& & & & 17,88 \\
Depósitos Cuaternarios & 218 & $\mathrm{~N} 80^{\circ}-90^{\circ} ; \mathrm{N} 170^{\circ}-180^{\circ}$ & & 16,18 \\
\hline
\end{tabular}

datos detectados es homogéneo o es polifásico y presenta importantes variaciones en el tiempo. Los resultados conseguidos respaldan la primera hipótesis, porque no se observan variaciones particulares entre estas rosas y las otras: siempre domina el rumbo E-W. Los datos referentes a los depósitos cuaternarios se encuentran al final de cada cuadro.
En los cuadros 4 y 5 se presentan los datos numéricos del análisis de la persistencia de los lineamientos. En el cuadro 4 se presenta el asunto en términos de frecuencia, o sea el número de lineamientos que caen en cada clase de longitud, mientras que en el cuadro 5 el análisis se ha hecho en términos de la longitud total, o sea en kilómetros de lineamientos que caen en cada clase 

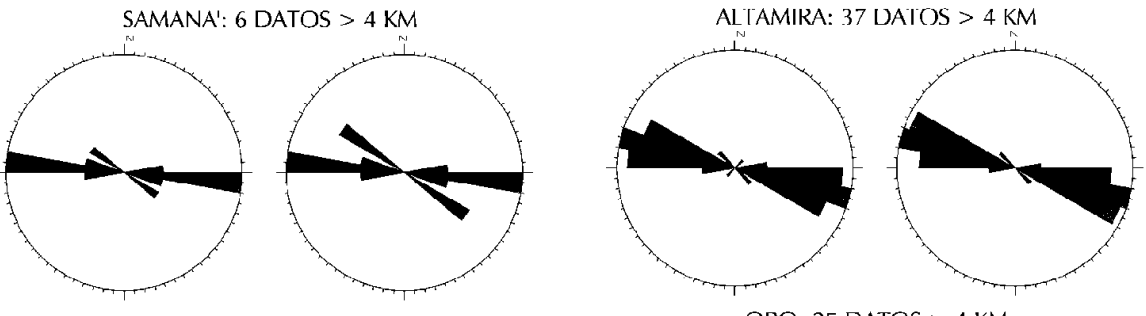

P.PLATA - P.GARCIA - R.S.JUAN: 49 DATOS $>4$ KM
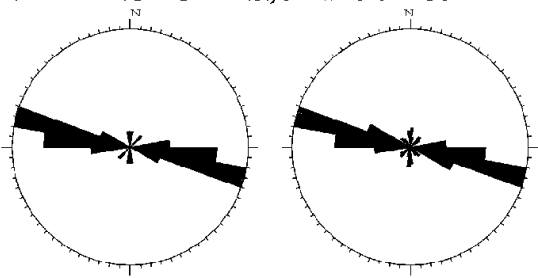

ORO: 25 DATOS $>4 \mathrm{KM}$
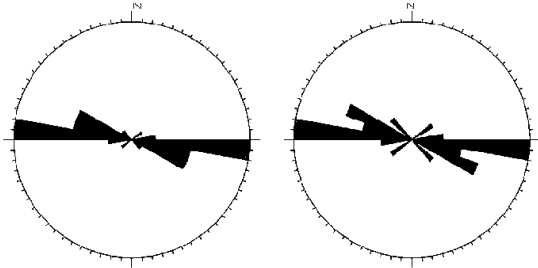

SEIBO: 141 DATOS $>4 \mathrm{KM}$

TIREO: 79 DATOS $>4 \mathrm{KM}$
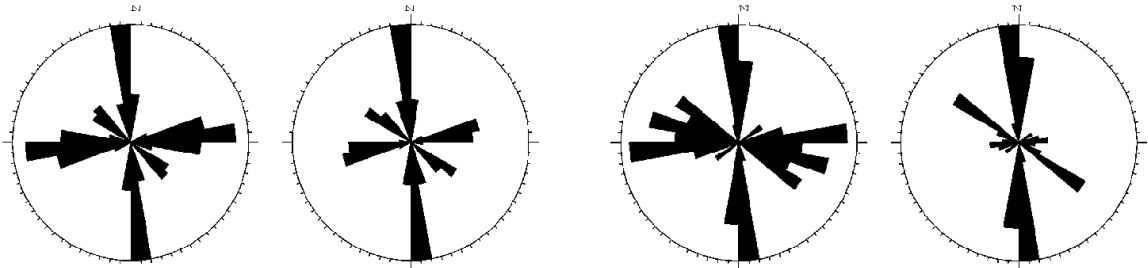

TORTUE - MAIMON - AMINA: 63 DATOS > 4 KM

TROIS RIVIERES - PERALTA: 65 DATOS > 4 KM
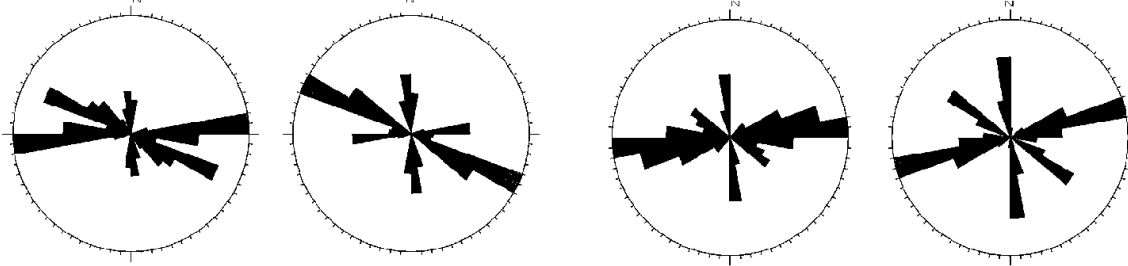

LOMA CARIBE - TAVERA: 43 DATOS $>4 \mathrm{KM}$

PRESQUILE DU NORD OUEST - NEIBA: 45 DATOS > 41
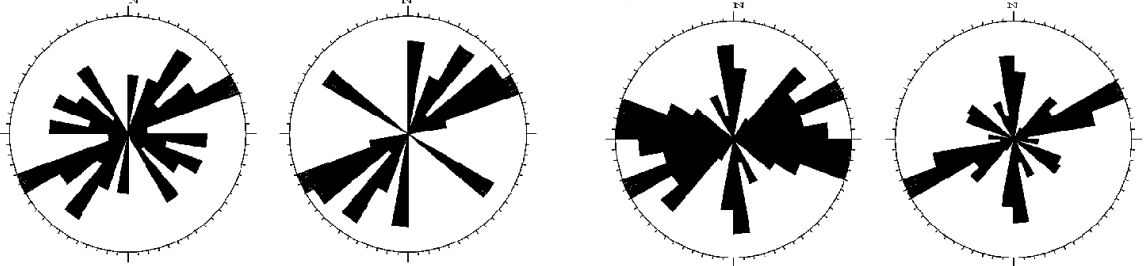

DUARTE: 102 DATOS $>4 \mathrm{KM}$

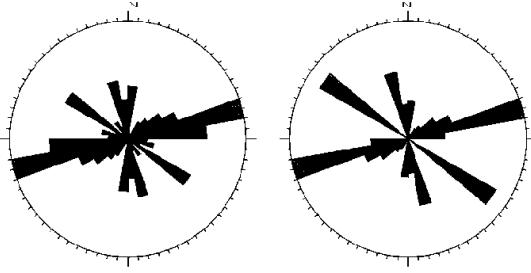

HOTTE - SALLE - BAHORUCO: 52 DATOS $>4 \mathrm{KM}$

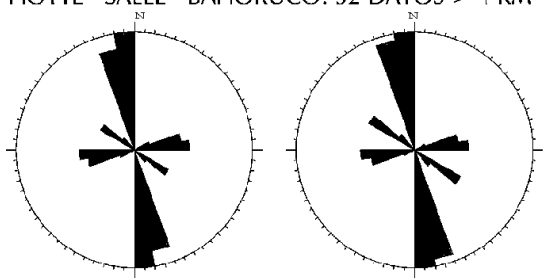

Fig. 5: Diagramas de las rosas de los datos mayores de $4 \mathrm{~km}$. Izquierda: rosa de frecuencia; derecha: rosa de longitud. 
de longitud. En ambos cuadros se presentan los valores absolutos y los porcentajes.

En el cuadro 6 se presentan (ya sea por cada terreno tectónico o por el campo total de los datos) algunos parámetros como el lineamiento más largo y el mediano, la densidad de lineamientos por $\mathrm{km}^{2}$, el peso estadístico de cada terreno respecto al total de los datos, ya sea como datos (número de lineamientos y longitud total) o como área. A partir de los datos totales presentados en los cuadros 4 y 5 se hicieron también diagramas columnares para confrontar los valores de la frecuencia con los de la longitud acumulativa (Figs. 6 y 7). En el primer diagrama se presentan los valores absolutos (Fig. 6) y en el segundo los valores relativos (\%) (Fig. 7).

Sobre los resultados del ánalisis de la persistencia cabe hacer algunas observaciones de caracter general. En lo que se refiere a la frecuencia, la mayoría de los datos $(95 \%)$ caen en las tres primeras clases de longitud $(<1 \mathrm{~km}, 1-2 \mathrm{~km}$ y $2-$ $4 \mathrm{~km})$. En general, los porcentajes promedios con que los datos van repartiéndose entre las 6 clases de longitud son un $37-45 \%$ en la primera $(<$ $1 \mathrm{~km}), 31-37 \%$ en la segunda (1-2 km), 18-19\% en la tercera $(2-4 \mathrm{~km}), 2,5-5 \%$ en la cuarta clase $(4-8 \mathrm{~km})$. Las últimas dos $(8-16 \mathrm{~km}$ y $>16 \mathrm{~km}) \mathrm{de}$ hecho no tienen peso estadístico, dado que en ningún terreno tectónico, ni a nivel de todo el país, alcanzan el $1 \%$. La primera clase es siempre la mayor, a excepción de los terrenos de Altamira y Tortue-Maimon-Amina donde, aunque por poco, prevalece la segunda. Claramente hay algunos terrenos tectónicos con comportamiento extremos, como Samaná y Trois Riviéres-Peralta donde la dominancia de las dos primeras clases de longitud es muy fuerte $(86 \%$ en Samaná y $81 \%$ en Trois Riviéres-Peralta), mientras en los de Hotte-Salle-Bahoruco, Loma Caribe-Tavera y sobretodo en Tortue-Maimon-Amina, el peso estadístico de los lineamientos más largos es mayor que en los otros: en estos tres terrenos los datos de las dos primeras clases juntas alcanzan solo un $70-72 \%$, contra un promedio de $74-77 \%$.

Cuadro 4

Análisis estadístico

Distribución por frecuencia de los lineamientos entre los terrenos tectónicos

\begin{tabular}{|c|c|c|c|c|c|c|c|c|c|c|c|c|c|}
\hline \multirow{2}{*}{$\begin{array}{l}\text { Terreno } \\
\text { Tectónico }\end{array}$} & \multicolumn{7}{|c|}{ Expresada como número de lineamientos } & \multicolumn{6}{|c|}{ Expresada en porcentaje } \\
\hline & TOT. & $\begin{array}{l}<1 \\
\mathrm{~km}\end{array}$ & $\begin{array}{l}1-2 \\
\mathrm{~km}\end{array}$ & $\begin{array}{l}2-4 \\
\mathrm{~km}\end{array}$ & $\begin{array}{l}4-8 \\
\mathrm{~km}\end{array}$ & $\begin{array}{c}8-16 \\
\mathrm{~km}\end{array}$ & $\begin{array}{r}>16 \\
\mathrm{~km}\end{array}$ & $\begin{array}{l}<1 \\
\mathrm{~km}\end{array}$ & $\begin{array}{l}1-2 \\
\mathrm{~km}\end{array}$ & $\begin{array}{l}2-4 \\
\mathrm{~km}\end{array}$ & $\begin{array}{l}4-8 \\
\mathrm{~km}\end{array}$ & $\begin{array}{c}8-16 \\
\mathrm{~km}\end{array}$ & $\begin{array}{l}>16 \\
\mathrm{~km}\end{array}$ \\
\hline 1 & 308 & 179 & 87 & 36 & 5 & 1 & & 58,12 & 28,25 & 11,69 & 1,62 & 0,32 & 0 \\
\hline 2 & 848 & 372 & 264 & 163 & 44 & 5 & & 43,87 & 31,13 & 19,22 & 5,19 & 0,59 & 0 \\
\hline 3 & 707 & 237 & 294 & 139 & 34 & 3 & & 33,52 & 41,58 & 19,66 & 4,81 & 0,42 & 0 \\
\hline 4 & 637 & 290 & 200 & 122 & 21 & 4 & & 45,53 & 31,4 & 19,15 & 3,3 & 0,63 & 0 \\
\hline 5 & 3261 & 1389 & 1133 & 598 & 137 & 4 & & 42,59 & 34,74 & 18,34 & 4,2 & 0,12 & 0 \\
\hline 6 & 1015 & 350 & 365 & 237 & 58 & 5 & & 34,48 & 35,96 & 23,35 & 5,71 & 0,49 & 0 \\
\hline 7 & 779 & 289 & 276 & 171 & 36 & 6 & 1 & 37,1 & 35,43 & 21,95 & 4,62 & 0,77 & 0,13 \\
\hline 8 & 2160 & 895 & 766 & 397 & 96 & 6 & & 41,44 & 35,46 & 18,38 & 4,44 & 0,28 & 0 \\
\hline 9 & 2135 & 850 & 794 & 412 & 74 & 5 & & 39,81 & 37,19 & 19,3 & 3,47 & 0,23 & 0 \\
\hline 10 & 2441 & 1180 & 817 & 379 & 61 & 4 & & 48,34 & 33,47 & 15,53 & 2,5 & 0,16 & 0 \\
\hline 11 & 1479 & 602 & 551 & 281 & 41 & 3 & 1 & 40,7 & 37,25 & 19 & 2,77 & 0,2 & 0,07 \\
\hline 12 & 1533 & 615 & 505 & 350 & 61 & 2 & & 40,12 & 32,94 & 22,83 & 3,98 & 0,13 & 0 \\
\hline
\end{tabular}

1: Samaná, 2: Puerto Plata-Pedro Garcia-Río San Juan, 3: Altamira, 4: Oro, 5: Seibo, 6: Tortue Maimon-Amina, 7: Loma Caribe-Tavera, 8: Duarte, 9:Tireo, 10: Trois-Riviéres-Peralta, 11: Presqu'Ile du Nord Ouest - Neiba, 12: Hotte-Salle-Bahoruco 
Cuadro 5

Análisis estadístico, distribución por longitud de los lineamientos entre los terrenos tectónicos

\begin{tabular}{|c|c|c|c|c|c|c|c|c|c|c|c|c|c|}
\hline \multirow{3}{*}{$\begin{array}{l}\text { Terreno } \\
\text { Tectónico }\end{array}$} & \multicolumn{7}{|c|}{ Expresada como número de lineamientos } & \multicolumn{6}{|c|}{ Expresada en porcentaje } \\
\hline & TOT. & $<1$ & $1-2$ & $2-4$ & $4-8$ & $8-16$ & $>16$ & $<1$ & $1-2$ & $2-4$ & $4-8$ & $8-16$ & $>16$ \\
\hline & & $\mathrm{km}$ & $\mathrm{km}$ & $\mathrm{km}$ & $\mathrm{km}$ & $\mathrm{km}$ & $\mathrm{km}$ & $\mathrm{km}$ & $\mathrm{km}$ & $\mathrm{km}$ & $\mathrm{km}$ & $\mathrm{km}$ & $\mathrm{km}$ \\
\hline 1 & 365,54 & 115,14 & 119,86 & 99,23 & 22,96 & 8,35 & & 31,5 & 32,79 & 27,15 & 6,28 & 2,28 & 0 \\
\hline 2 & 1331,03 & 242,75 & 381,43 & 432,74 & 228,38 & 45,73 & & 18,24 & 28,66 & 32,51 & 17,16 & 3,44 & 0 \\
\hline 3 & 1175,61 & 164,67 & 418,23 & 375,64 & 186,39 & 30,67 & & 14,01 & 35,58 & 31,95 & 15,85 & 2,61 & 0 \\
\hline 4 & 939,93 & 184,69 & 276,19 & 327,91 & 110,1 & 41,04 & & 19,65 & 29,38 & 34,89 & 11,71 & 4,37 & 0 \\
\hline 5 & 4889,45 & 927,9 & 1610,94 & 1615,42 & 699,47 & 35,72 & & 18,89 & 32,95 & 33,04 & 14,31 & 0,73 & 0 \\
\hline 6 & 1757,06 & 240,83 & 509,68 & 653,1 & 307,14 & 46,31 & & 13,71 & 29,01 & 37,17 & 17,48 & 2,64 & 0 \\
\hline 7 & 1311,88 & 200,92 & 389,49 & 469,62 & 178,17 & 56,43 & 17,25 & 15,32 & 29,69 & 35,8 & 13,58 & 4,3 & 1,31 \\
\hline 8 & 3323,02 & 612,38 & 1071,68 & 1081,43 & 496,3 & 61,23 & & 18,43 & 32,25 & 32,54 & 14,94 & 1,84 & 0 \\
\hline 9 & 3261,58 & 604,18 & 1097,94 & 1136,38 & 372,14 & 50,94 & & 18,52 & 33,66 & 34,84 & 11,41 & 1,56 & 0 \\
\hline 10 & 3278,78 & 795,15 & 1135,14 & 1012,05 & 297,61 & 38,82 & & 24,25 & 34,62 & 30,87 & 9,08 & 1,18 & 0 \\
\hline 11 & 2206,26 & 403,49 & 777,26 & 776,61 & 204,05 & 28,28 & 16,57 & 18,29 & 35,23 & 35,2 & 9,25 & 1,28 & 0,75 \\
\hline 12 & 2401,39 & 413,3 & 713,26 & 948,25 & 306,55 & 20,02 & & 17,21 & 29,7 & 39,49 & 12,77 & 0,83 & 0 \\
\hline
\end{tabular}

1: Samaná, 2: Puerto Plata-Pedro Garcia-Río San Juan, 3: Altamira, 4: Oro, 5: Seibo, 6: Tortue Maimon-Amina, 7: Loma Caribe-Tavera, 8: Duarte, 9:Tireo, 10: Trois-Riviéres-Peralta, 11: Presqu'Ile du Nord Ouest - Neiba, 12: Hotte-Salle-Bahoruco.

Cuadro 6

Análisis estadístico, resumen

\begin{tabular}{|c|c|c|c|c|c|c|c|c|c|c|}
\hline \multirow{2}{*}{$\begin{array}{l}\text { Terreno } \\
\text { Tectónico }\end{array}$} & \multirow[b]{2}{*}{ TOT. } & \multirow[t]{2}{*}{$\%$ Frec. } & \multirow[b]{2}{*}{ TOT. } & \multirow{2}{*}{$\begin{array}{c}\% . \\
\text { Longitud }\end{array}$} & \multicolumn{2}{|c|}{ Longitud } & \multirow{2}{*}{$\begin{array}{l}\text { Area } \\
\mathrm{km}^{2}\end{array}$} & \multirow{2}{*}{$\begin{array}{c}\% \\
\text { Area }\end{array}$} & \multicolumn{2}{|c|}{ Densidad } \\
\hline & & & & & Max & Med & & & Lin. / área & $\mathrm{km} / \mathrm{km}^{2}$ \\
\hline 1 & 308 & 1,78 & 365,54 & 1,39 & 8,35 & 1,19 & 606,5 & 1,28 & 0,51 & 0,6 \\
\hline 2 & 848 & 4,9 & 1331,03 & 5,07 & 11,62 & 1,57 & 3841,9 & 7,71 & 0,22 & 0,35 \\
\hline 3 & 707 & 4,09 & 1175,61 & 4,48 & 14,62 & 1,66 & 2202,8 & 4,42 & 0,32 & 0,53 \\
\hline 4 & 637 & 3,68 & 939,93 & 3,58 & 12,86 & 1,48 & 1620,5 & 3,25 & 0,39 & 0,58 \\
\hline 5 & 3261 & 18,85 & 4889,45 & 18,63 & 10,1 & 1,5 & 14475,4 & 29,06 & 0,23 & 0,34 \\
\hline 6 & 1015 & 5,87 & 1757,06 & 6,7 & 10,98 & 1,73 & 2677,9 & 5,38 & 0,38 & 0,66 \\
\hline 7 & 779 & 4,5 & 1311,88 & 5 & 17,25 & 1,68 & 1788,1 & 3,59 & 0,44 & 0,73 \\
\hline 8 & 2160 & 12,48 & 3323,02 & 12,66 & 11,99 & 1,54 & 4928,8 & 9,9 & 0,44 & 0,67 \\
\hline 9 & 2135 & 12,33 & 3261,58 & 12,43 & 11,64 & 1,53 & 3536,6 & 7,1 & 0,6 & 0,92 \\
\hline 10 & 2441 & 14,1 & 3278,78 & 12,49 & 10,64 & 1,34 & 3437,1 & 6,9 & 0,71 & 0,95 \\
\hline 11 & 1479 & 8,55 & 2206,26 & 8,41 & 16,57 & 1,49 & 4521,7 & 9,08 & 0,33 & 0,49 \\
\hline 12 & 1533 & 8,86 & 2401,39 & 9,15 & 11,03 & 1,57 & 6164,4 & 12,38 & 0,25 & 0,39 \\
\hline Total & 17303 & 100 & 26241,53 & 100 & 17,25 & 1,52 & 49801,7 & 100 & 0,35 & 0,53 \\
\hline
\end{tabular}

1: Samaná, 2: Puerto Plata-Pedro Garcia-Río San Juan, 3: Altamira, 4: Oro, 5: Seibo, 6: Tortue Maimon-Amina, 7: Loma Caribe-Tavera, 8: Duarte, 9:Tireo, 10: Trois-Riviéres-Peralta, 11: Presqu'Ile du Nord Ouest - Neiba, 12: Hotte-Salle-Bahoruco 


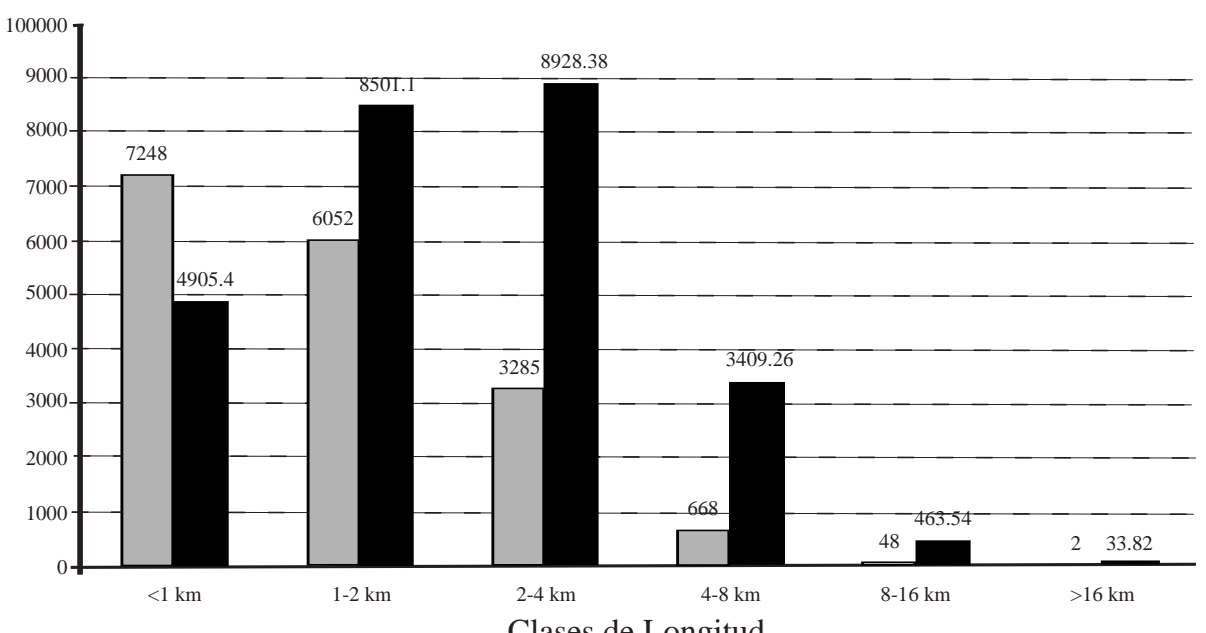

Frecuencia

Longitud

Clases de Longitud

Fig. 6: Comparación entre frecuencia y longitud de las clases de longitud de lineamientos

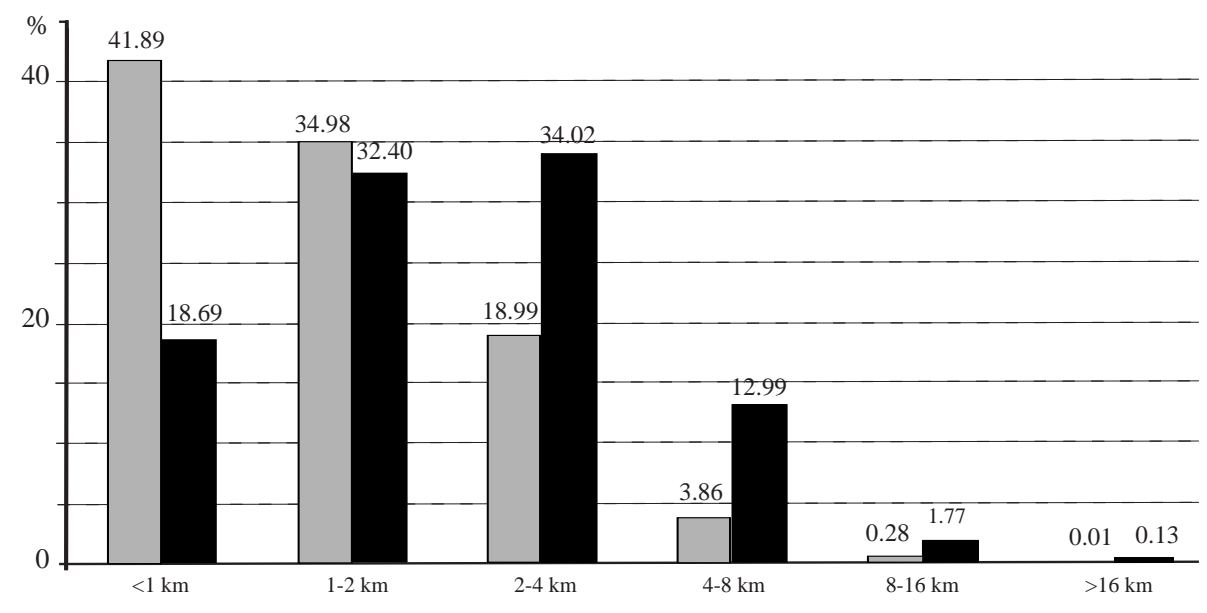

Clases de Longitud

Frecuencia número de lineamientos por clase Longitud $\mathrm{km}$ de lineamientos por clase

Fig. 7: Comparación entre frecuencia y longitud de las clases de longitud de lineamientos (expresadas como porcentaje)

En lo que se refiere a la longitud, en general las consideraciones que se pueden hacer son muy similares a las anteriores. También, en este caso, las primeras tres clases de longitud incluyen la mayoría de los datos (80-90\%). En general, los porcentajes promedios con que los datos van repartiéndose entre las 6 clases de longitud son un $17-20 \%$ en la primera $(<1 \mathrm{~km}), 29-35 \%$ en la se- gunda (1-2 km), 30-39\% en la tercera (2-4 km), 9$17 \%$ en la cuarta $(4-8 \mathrm{~km})$ y $1-3 \%$ en la quinta (8$16 \mathrm{~km})$ aunque en Oro y Loma Caribe-Tavera alcance más del $4 \%$. La sexta clase (>16 km) de hecho no tiene peso estadístico. La clase de longitud más importante es la tercera $(2-4 \mathrm{~km})$, aunque en los terrenos tectónicos de Samaná, Altamira y Trois Riviéres-Peralta predomine la segunda. 
De los datos presentados en el cuadro 6 seguramente los más interesantes son la longitud media y la densidad de lineamientos. La primera varía según el terreno tectónico entre 1,19 y 1,73 $\mathrm{km}$ con un promedio de 1,52-1,56 km, contra valores de longitud máximas de 10-17 km.

Los promedios más altos corresponden con los terrenos de Altamira (1,66), Loma Caribe-Tavera $(1,68)$ y Tortue-Maimon-Amina $(1,73)$, mientras el más bajo le corresponde a Samaná $(1,19)$.

La densidad de lineamientos, considerando todo el territorio de la República Dominicana es de $0,53 \mathrm{~km} / \mathrm{km}^{2}\left(\mathrm{~km}\right.$ de lineamientos por $\mathrm{km}^{2}$ de territorio). En cambio, considerando cada terreno tectónico se puede observar que los terrenos de la parte central de la Isla Española presentan los valores más altos: Trois Riviéres-Peralta $0,95 \mathrm{~km} / \mathrm{km}^{2}$, Tireo 0,92 , Loma Caribe-Tavera 0,73 , Duarte 0,67 y Tortue-Maimon-Amina $0,66 \mathrm{~km} / \mathrm{km}^{2}$. Los valores más bajos corresponden con los terrenos de puerto Plata-Pedro García-río San Juan $(0,35)$ y Seibo $(0,34)$.

En los siguientes párrafos se analizarán los resultados obtenidos en cada terreno tectónico.

\section{TERRENO TECTÓNICO SAMANÁ}

Es el más pequeño de los terrenos tectónicos y es el que presenta un menor número de datos (solamente 308). Está constituido por fajas de rocas metamórficas de alta presión conectadas con un prisma de acreción del Cretáceo Superior, que aflora al norte de la SFZ (septentrional fault zone) en la zona de Samaná.

El rumbo principal permanece E-W (de $\mathrm{N} 90^{\circ}$ a $\mathrm{N} 110^{\circ}$ ) en cualquier diagrama (total mayores de $2 \mathrm{~km}$ y mayores de $4 \mathrm{~km}$ ). Los lineamientos $\mathrm{N} 90^{\circ}-100^{\circ}$ parecen relacionados a estructuras transcurrentes izquierdas, que son también las más continuas (>4 km); los N100$110^{\circ}$ parecen relacionados con estructuras transpresivas. Hay también estructuras de rumbo NE-SW y N-S las cuales, sin embargo, son de longitud $<2 \mathrm{~km}$, y solo se observan en las rosas de todos los datos. Las estructuras NESW tienen carácter extensional y constituyen pequeñas cuencas de pull-apart entre fallas E$\mathrm{W}$ izquierdas. La costa oriental de la península de Samaná podría ser cortada por fallas extensionales de este tipo, mientras las fallas N-S podrían corresponder con fallas secundarias $\mathrm{R} 1$ derechas.

La transcurrencia resulta seguramente más reciente a lo largo del límite sur del bloque. Las estructuras orogénicas más antiguas resultan poco visibles en el mapa. Los lineamientos de este sector son muy pequeños: el $58 \%$ son de longitud $<1 \mathrm{~km}$, pero la densidad de lineamientos $(0,6$ $\mathrm{km} / \mathrm{km}^{2}$ ) es un poco más alta con respeto al promedio general $(0,53)$.

\section{TERRENO TECTÓNICO PUERTO PLATA - PEDRO GARCÍA - RÍO SAN JUAN}

Este terreno tectónico está constituído por rocas metamórficas. Está delimitado al SW por la RGFZ (Rio Grande fault zone) que se conecta a la CFZ (Camu fault zone) y al sur por la SFZ. También en este sector hay transcurrencia a lo largo de estructuras E-W (las más frecuentes en el área) y transpresión sobre fallas subverticales a lo largo de estructuras marcadas por lineamientos WNW-ESE $\left(\mathrm{N} 100^{\circ}-110^{\circ}\right)$, paralelos a la RGFZ. Estos últimos lineamientos resultan más evidentes en las rosas considerando solo los datos mayores de $4 \mathrm{~km}$ y esto indica que son estructuras de gran persistencia.

También, siempre aparece una pequeña, pero bien marcada, familia de lineamientos N-S. El hecho de que va desapareciendo en el diagrama de los lineamientos mayores de $4 \mathrm{~km}$ muestra que esta familia esta constituída sobretodo por lineamientos pequeños. Estos lineamientos N-S podrían corresponder con fallas laterales secundarias (R1) derechas que se formaron entre las principales fajas de cizalle con movimiento izquierdo y rumbo E-W.

Los lineamientos NE-SW son poco evidentes en las rosas y podrían corresponder con fallas extensionales. La mayoría de las estructuras se observan en rocas recientes plio-pleistocénicas. 


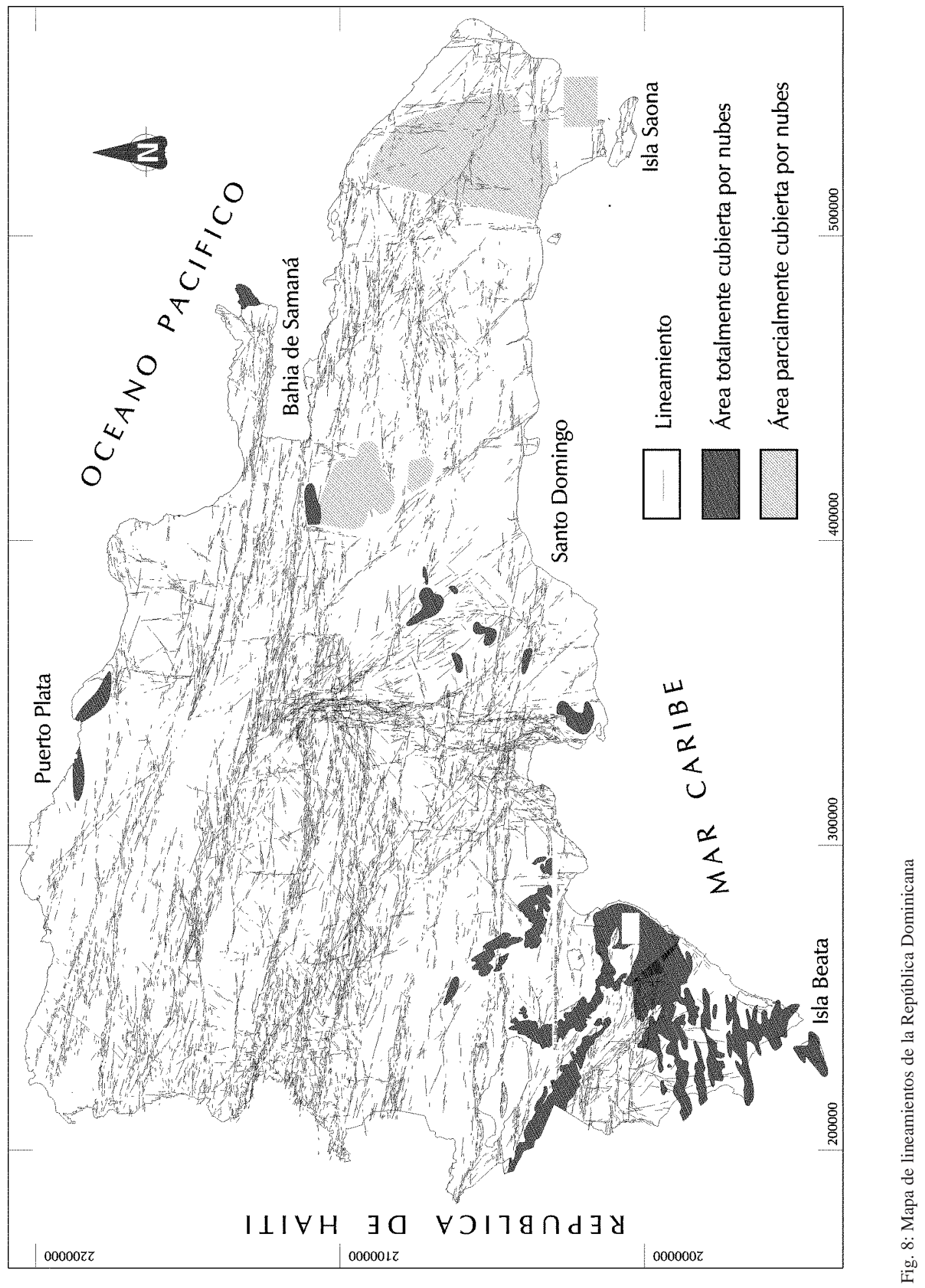




\section{TERRENO TECTÓNICO ALTAMIRA}

Este sector comprende sucesiones volcano-clásticas de arco de islas. El terreno tectónico está delimitado al sur por la SFZ y al NE por la RGFZ. También, aquí se presentan fenómenos de transcurrencia a lo largo de estructuras E-W (que corresponden con los lineamientos más frecuentes) y de transpresión a lo largo de estructuras $\mathrm{N} 100^{\circ}-100^{\circ}$ (las más extensas $>4 \mathrm{~km}$ ).

La SFZ está caracterizada en su conjunto por transpresión con componentes de cabalgamiento vergentes hacia el sur. La zona de Punta El Morro está afectada por fallas transcurrentes izquierdas de análoga orientación, mientras poco al sur hay fallas inversas.

Lineamientos con rumbo NE-SW pueden corresponder con estructuras extensionales activas (pequeñas cuencas de pull-apart) o estructuras más antiguas.

\section{TERRENO TECTÓNICO ORO}

Está constituído por sucesiones volcanoclásticas de arco de islas, tectónicamente abajo del terreno tectónico Seibo.

Dominan los lineamientos con rumbo $\mathrm{N} 90^{\circ}-100^{\circ}$, que probablemente corresponden con estructuras transcurrentes y transpresivas. Subordinadamente están presentes también lineamientos con rumbos $\mathrm{N}-\mathrm{S}$, que tienen persistencia mediana (de 2 a $4 \mathrm{~km}$ ) y significado poco claro. Las estructuras WNW-ESE presentan una buena persistencia $(>4 \mathrm{~km})$ y probablemente se deben interpretar como viejos cabalgamientos, tal vez reactivados por el actual régimen de esfuerzos.

\section{TERRENO TECTÓNICO SEIBO}

Se trata del terreno tectónico más amplio (cubre el 29\% del territorio dominicano) y que cruza toda la isla en sentido longitudinal. Incluye sobretodo rocas del tipo metavulcanitas de arco, que cubren tectónicamente el terreno tectónico Oro. Desde el punto de vista estructural, este sector incluye algunas de las áreas más activas (va- lle del Cibao, valle de la Vega Real, bahía de Samaná) y resulta delimitado al norte por la SFZ y al sur por la HAFZ (Hatillo fault zone). La falla Septentrional está bien documentada, en la literatura; se trata de una estructura en "flor" que se ha desarrollado a lo largo de un restraining bend de un sistema trascurrente izquierdo. Hay una buena correspondencia entre los lineamientos identificados y las estructuras activas que se describen en la literatura.

Los lineamientos dominantes E-W (más frecuentes) corresponden con fallas transcurrentes izquierdas, los NW-SE con fallas inversas (cabalgamientos y pliegues), los N-S (más extensos, $>4 \mathrm{~km}$ ) con fallas transcurrentes derechas $\mathrm{y}$, finalmente, los NE-SW (muy escasos y pequeños) con fallas extensionales. Este cuadro resulta bien representado en los valles del Cibao y de la Vega Real, mientras en el sector de la Cordillera Oriental muchos lineamientos NW-SE (dominantes en esta zona) corresponden probablemente con viejas estructuras compresivas, tal vez parcialmente reactivadas. También, los lineamientos $\mathrm{N}-\mathrm{S}$ en esta parte del terreno tectónico resultan de difícil caracterización: es posible que el campo de esfuerzos inducido por el prisma de Los Muertos se sobreponga al campo de esfuerzos presente en los otros sectores, generando anomalías respecto al régimen principal.

El terreno tectónico donde se han detectado más lineamientos (3261, o sea el 18,63\% de todos los datos), a causa de su gran extensión; es también el que tiene la densidad de lineamientos más baja: $0,34 \mathrm{~km} / \mathrm{km}^{2}$.

\section{TERRENO TECTÓNICO TORTUE-MAIMON-AMINA}

Este sector incluye una delgada faja de rocas metamórficas que cruza toda la isla, llegando hasta la Isla Tortuga. Las rocas incluyen metabasaltos y metasedimentos, cuya origen esta relacionada con un ambiente de arco volcánico. El sector está delimitado por la HAFZ hacia el norte y la HFZ hacia el sur. La HZF delimita al sur el valle de Cibao y la costa norteña de la República de Haití, conectándose al oeste de la isla 
Tortuga con la OFZ (Oriental fault zone), que constituye el límite norte de la microplaca Gonave.

Los lineamientos reconocidos en este sector parecen coincidir con las fallas laterales izquierdas E-W descritas en la literatura y con cabalgamientos con rumbo NW-SE, probablemente más antiguos y en parte reactivados; estos últimos se encuentran sobretodo en la parte oriental del sector. Además, se encuentran lineamientos con rumbo N-S y NE-SW, que corresponden respectivamente con fallas laterales derechas y con fallas extensionales. Los lineamientos N-S se concentran en la porción central del terreno en donde parecen representar la cola más septentrional de un haz de estructuras, procedentes del costado oriental de la Bahía de Ocoa y que corresponden probablemente con una zona de desvío y cierre occidental (lateral ramp) del prisma de acreción de Los Muertos. Esta zona de cizalle parece ha estado activa desde la estructuración más antigua de la cordillera.

El diagrama de los datos mayores de $2 \mathrm{~km}$ muestra que los lineamientos E-W $\left(\mathrm{N} 80^{\circ}-90^{\circ}\right)$ prevalecen en número, pero las familias $\mathrm{N}-\mathrm{S}$ y NW-SE $\left(\mathrm{N} 120^{\circ}-130^{\circ}\right)$ contienen lineamientos caracterizados por una mayor persistencia (en la rosa de la longitud son muchos más marcados que en la de la frecuencia). El diagrama de los datos de longitud mayor de $4 \mathrm{~km}$ ofrece indicaciones casi análogas: la clase $\mathrm{N} 80^{\circ}-90^{\circ}$ domina en la rosa de la frecuencia y la $\mathrm{N} 110^{\circ}-120^{\circ}$ en la de la longitud de los lineamientos.

\section{TERRENO TECTÓNICO LOMA CARIBE -TAVERA}

Este sector representa un fragmento de fondo oceánico y forma una delgada faja paralela al sector anterior y ubicada al sur del mismo. Las rocas son representadas por serpentinitas muy deformadas a lo largo de la HFZ y sedimentos terciarios. Los movimientos a lo largo de la HFZ parece que empezaron en el Oligoceno con componentes laterales izquierdas.

Con respecto a los sectores anteriormente descritos, las familias de lineamientos son las mismas y tienen el mismo significado cinemático.
En el diagrama total, además del rumbo principal E-W, hay uno menor $\mathrm{N} 130^{\circ}-140^{\circ}$. En el diagrama de los datos mayores de $2 \mathrm{~km}$, la rosa de la frecuencia muestra que los datos están distribuidos entre la clase de rumbo principal $\mathrm{N} 80^{\circ}$ $90^{\circ}$, la secundaria $\mathrm{N} 120^{\circ}-130^{\circ}$ y una tercera familia más pequeña con rumbo $\mathrm{N} 160^{\circ}-170^{\circ}$. En la rosa de la longitud domina la clase $\mathrm{N} 120^{\circ}-130^{\circ}$. En el diagrama de los datos mayores de $4 \mathrm{~km}$ hay una gran dispersión de datos, a pesar de que el rumbo principal es NE-SW $\left(\mathrm{N} 50^{\circ}-60^{\circ}\right)$.

\section{TERRENO TECTÓNICO DUARTE}

Está constituído por metabasitas con grado variable de metamorfismo (facies prehnitapumpellita hasta facies anfibolita) intruídas por rocas graníticas cretáceo-terciarias; las rocas originarias de las metabasitas (basaltos) representan un fragmento de corteza oceánica engrosada tipo seamount o isla oceánica. El complejo está en su totalidad constituído por rocas metamórficas con foliación subvertical, que cruzan toda la isla. El sector está delimitado al SW por la GFZ y hacia el SE por la BFZ; ambas estructuras parecen fallas transcurrentes subverticales.

Las familias de lineamientos son las mismas que los de los sectores precedentes, pero hay un fuerte aumento de importancia de la familia $\mathrm{N}$ $\mathrm{S}$, en fuerte conexión con la torsión de la unidad en el área de Bonao de un rumbo NW-SE a un rumbo $\mathrm{N}-\mathrm{S}$. Muchos de los lineamientos parecen conectados con elementos estructurales pre-neogénicos (foliaciones y fallas connectados con las fases deformativas que han afectado el complejo mismo).

En el diagrama que utiliza todos los datos, el rumbo principal E-W se combina con un rumbo menor N-S, más marcado en la rosa de la frecuencia que en la de la longitud. La eliminación de los lineamientos más pequeños $(<2 \mathrm{~km})$ permite evidenciar tres familias de datos: WSW-ENE $\left(\mathrm{N} 70^{\circ}-90^{\circ}\right), \mathrm{NW}-\mathrm{SE}\left(\mathrm{N} 120^{\circ}-130^{\circ}\right)$ e NNW-SSE $\left(\mathrm{N} 170^{\circ}\right)$. En la rosa de la longitud la primera y la tercera familia pierden un poco de importancia. En el diagrama de los datos mayores de $4 \mathrm{~km}$ hay las mismas familias, pero la más importante es la de rumbo WSW-ENE. 


\section{TERRENO TECTÓNICO TIREO}

Este sector incluye volcanoclastitas y lavas del Cretácico, intruídas por rocas graníticas de edad del Cretácico tardío-Eoceno. Está delimitado al norte por las GFZ y BFZ y al sur por la SJRFZ (San José-Restauración fault zone) y constituye el núcleo de la Cordillera Central. La SJRFZ representa una zona de transpresión izquierda con rumbo NW-SE, donde este mismo complejo sobrecorre hacia SW al adyacente complejo Trois Riviéres - Peralta.

Las familias reconocidas son las mismas que están presentes en los otros complejos tectónicos, con una fuerte dominancia de los lineamientos E-W.

El diagrama purificado de los lineamientos más cortos de $2 \mathrm{~km}$ muestra como en la rosa de la frecuencia están bien evidentes los 4 rumbos principales (que no se podían observar en el diagrama de todos los datos). En orden de importancia decreciente: E-W, N-S, NW-SE y NE-SW. En la rosa de la longitud del mismo diagrama, los rumbos N-S y NW-SE son claramente los más importantes enfatizando una persistencia muy importante. En el diagrama de los lineamientos mayores de $4 \mathrm{~km}$ se pueden hacer observaciones en su mayoría parecidas. En este caso, como ya se ha dicho acerca de la zona Seibo, el diagrama enfatiza la importancia de la familia N-S. Estas estructuras son relacionadas con la torsión del complejo Duarte.

\section{TERRENO TECTÓNICO TROIS RIVIÉRES - PERALTA}

Se derarrolla entre la SJRFZ al norte y la LPSJFZ (Los Pozos-San Juan fault zone) al sur, ambas estructuras de tipo inverso (transpresivas izquierdas) con buzamiento de ángulo mediano y vergentes hacia el SSW. La LPSJZF a veces viene conectada con el desvío lateral derecho del prisma de Los Muertos en correspondencia con la bahía de Ocoa y por ende parece ser una estructura activa de gran importancia. El complejo incluye sucesiones turbidíticas discordantes entre ellas y de edad comprendida entre el Cretácico y el Pleistoceno.
Los lineamientos reconocidos en este sector se diferencian de los del sector precedente en lo que se refiere a la frecuencia relativa. Los lineamientos E-W se encuentran por todo lado, pero sobre todo en la porción norte de la Bahía de Ocoa, en donde coinciden con la terminación oriental de la EPGFZ, aquí representada por la falla activa Azua. Los lineamientos N-S coinciden con un haz de fallas que limita al oeste con el prisma de accreción de Los Muertos y que presenta componentes de desplazamientos lateral derechos. Las estructuras NE-SW representan un sistema de fallas extensionales (Beata Fault Zone) que sigue en el mar en el Beata Ridge. Parece que este sistema de fallas tiene componentes de movimiento de tipo transtensivo derecho. Estas estructuras tienen una gran importancia en la parte central del sector, porque a lo largo de estas se ha originada la actividad volcánica Plio-Cuaternaria presente también en el sector adyacente al sur. Los lineamientos NW-SE corresponden tanto con cabalgamientos como con pliegues. Los lineamientos E-W, NW-SE, y N-S parecen en parte seguir la torsión en sentido horario de las estructuras que se observan en los alrededores de la bahía de Ocoa y al NW de la misma.

\section{TERRENO TECTÓNICO PRESQU'ILE DU NORD OUEST - NEIBA}

Este sector incluye sucesiones volcánicas y volcanoclásticas de ambiente de arco insular, cubiertas en discordancia por calizas paleocénicas de mar profundo. Este terreno tectónico pertenece a la microplaca Gonave y está incluido entre la LPSJFZ al norte y la EPGFZ al sur. El complejo sobrecorre al complejo de Hotte-SalleBahoruco a lo largo de una superficie de corrimiento vergente hacia el sur, cortado por la EPGFZ. En la parte norteña, inmediatamente al sur de la LPSJFZ, se ubica la depresión del valle de San Juan con estructura sinclinarica, delimitada al sur por la Sierra de Neiba, que representa una estructura tipo pop-up con rumbo E-W, a su vez bruscamente cortada por la EPGFZ. En el Valle de San Juan se encuentra actividad volcánica en dos áreas distintas, ambas caracterizadas 
por la alineación de los centros de emisión con rumbo NE-SW. Pliegues en échelon con eje NWSE se encuentran al norte de la EPGFZ y en su continuación al oeste.

Los lineamientos dominantes corresponden con estructuras de rumbo E-W $\left(\mathrm{N} 80^{\circ}-110^{\circ}\right.$, véase las rosas referentes a todo el conjunto de los datos) que forman fajas paralelas y aisladas, que corresponden sobretodo con cabalgamientos y con pliegues vergentes hacia el norte y con fallas transcurrentes izquierdas en la parte sur, paralelas o coincidentes con la EPGFZ.

La eliminación de los lineamientos más pequeños evidencia una neta dispersión de los datos remanentes, por lo menos en las rosas de frecuencia. Sin embargo, se reconocen tres rumbos principales NNW-SSE (N-S en el diagrama de los datos mayores de $4 \mathrm{~km}), \mathrm{NW}-\mathrm{SE}\left(\mathrm{N} 120^{\circ}\right)$ y NE-SW $\left(\mathrm{N} 70^{\circ}\right)$. En el gráfico de los datos mayores de $2 \mathrm{~km}$ prevale el rumbo NNW-SSE. En el otro, el rumbo dominante es el NE-SW.

Todas las estructuras identificadas presentan una buena persistencia (el segundo lineamiento por longitud, de 16,5 km de largo, se encuentra en este sector) y esto porque corresponden con sistemas de fallas activas.

\section{TERRENO TECTÓNICO HOTTE-SALLE-BAHORUCO}

Este complejo incluye un fragmento de un plateau oceánico constituído por basaltos del Cretácico Superior intercalados con sedimentos pelágicos y cubierto por discordancia por una sucesión carbonática de edad paleo-miocénica. El complejo está limitado al norte por la EPGFZ y al este por la Beata fault zone, que separa este sector de la corteza oceánica de la placa caribeña, que forma el Beata Ridge.

Esta zona constituye la parte más sureña de la isla e incluye la sierra Bahoruco, con pliegues y cabalgamientos (thrust) vergentes hacia el norte y con rumbo E-W y ESE-WNW. El límite septentrional del sector, representado por la EPGFZ, ha sido bien estudiado. También, esta zona tiene un carácter transpresivo con pliegues asociados en échelon y un ramp basin sinforme (lago de Enriquillo). Muy compleja resulta la terminación oriental de este sector, que parece indentarse a lo largo de la Beata fault zone con el Beata ridge de pertenencia caribeña.

En los diagramas de rosas se observan las siguientes familias: $\mathrm{E}-\mathrm{W}\left(\mathrm{N} 90^{\circ}-100^{\circ}\right)$ dominante tanto en las rosas totales, como en aquellas con solo los datos de longitud mayor de $2 \mathrm{~km}$; NW$\mathrm{SE}\left(\mathrm{N} 130^{\circ}-140^{\circ}\right)$ dominante en las rosas de los datos con longitud mayor de $4 \mathrm{~km}$ (o sea son lineamientos muy extensos) y se reconoce bien en todas las otras familias; N-S y NE-SW que son las familias menos importantes, pero se reconocen en todas las rosas.

Los lineamientos E-W corresponden sobretodo con la EPGFZ y con pliegues y cabalgamientos presentes en la Sierra de Bahoruco y a lo largo del costado meridional de la Hoya de Enriquillo. Las fallas N-S y NE-SW representan estructuras de desvio del Beata Ridge, con unas componentes transtensivas, presentes sobretodo a lo largo de la costa oriental de la península entre la isla Beata y la bahía de Ocoa.

Finalmente, los lineamientos NW-SE representan estructuras presentes en la sierra de Bahoruco que coinciden sobretodo con fallas.

\section{CONCLUSIONES}

El estudio de las imágenes satelitales LANDSAT-TM de la República Dominicana ha permitido detectar 17300 lineamientos para una longitud total de más de $26200 \mathrm{~km}$.

El análisis estadístico de la distribución radial de estos lineamientos ha permitido reconocer que el territorio dominicano está afectado por 4 familas principales de estructuras: E-W $\left(\mathrm{N} 90^{\circ}-100^{\circ}\right)$, WNW-ESE, NW-SE, NE-SW.

Los lineamientos E-W son los más frecuentes y de mayor peso estadístico; en la mayor parte (pero no exclusivamente) son bastante cortos, como se puede comprender observando como cambia la configuración de los diagramas en rosas, eliminando los lineamientos menores de 2 y $4 \mathrm{~km}$ de longitud.

Las otras familias, aunque menos representativas que la familia E-W, tanto por número 
de datos como por longitud acumulada, se caracterizan por tener lineamientos de longitud mayor (> $4 \mathrm{~km})$.

El modelo cinemático reconstruido con base en los datos disponibles en la literatura permite interpretar de manera coherente el significado estructural de estas familias.

Los lineamientos E-W son preferencialmente interpretados como fallas laterales izquierdas (por ejemplo la EPGFZ).

Los lineamientos NW-SE corresponden con estructuras compresionales como sobrecorrimientos, pliegues, fallas inversas con inclinación elevada, mientras los lineamientos WNW-ESE corresponden con fallas laterales izquierdas de tipo transpresional (por ejemplo la SFZ).

Los lineamientos NE-SW corresponden con estructuras extensionales.

Los lineamientos N-S son interpretados como fallas laterales secundarias derechas tipo Riedel R1.

En algunos sectores (Cordillera Central y Oriental) este cuadro puede complicarse a causa de la presencia de estructuras más antiguas reactivadas.

Todos estos elementos son coherentes con un campo de esfuerzos caracterizado por un eje principal de compresión horizontal y con rumbo cercano al NE-SW.

Durante este estudio se ha tenido también la oportunidad de hacer en el campo algunas estaciones estructurales de control y los datos de campo en la mayoría de los casos se pueden relacionar fácilmente con las familias de lineamientos principales ya mencionadas y son coherentes con este modelo cinemático.

Con respecto a la longitud y persistencia de estos lineamientos, del análisis estadístico resulta que el $95 \%$ de ellos tiene una longitud menor de $4 \mathrm{~km}$. En particular aquellos de longitud entre $0-1 \mathrm{~km}$ son los más frecuentes (40\% y más del total de todos los datos), mientras los que estan entre 2-4 km son los más importantes de acuerdo con la longitud acumulativa (34\% del total). Los lineamientos con longitud mayor de 4 $\mathrm{km}$ son muy escasos.
Los cinco terrenos tectónicos que constituyen la parte central de la isla Española son los que presentan la mayor densidad de lineamientos. En particular los dos al sur (Tireo y Trois Riviéres-Peralta) son los más densos en términos absolutos con valores respectivamente de 0,92 y $0,95 \mathrm{~km}$ de lineamientos por cada $\mathrm{km}^{2}$, contra un promedio general de 0,53, mientras los dos más norteños (Loma Caribe-Tavera y Tortue-Maimon-Amina) se caracterizan por tener lineamientos con promedios de longitud más altos que los otros terrenos tectónicos.

Precisamente en la parte oriental de estos cinco sectores se ubica una faja con rumbo N-S, entre la bahía de Ocoa, Bonao y Jima Abajo, donde hay una concentración muy importante de lineamientos NNW-SSW, NW-SE y E-W. Esta estructura puede representar un segmento de la margen de la microplaca de Gonave.

El volcanismo plio-pleistocénico asociado con las estructuras extensionales NESW y el hecho que muchas veces estos lineamientos cruzan unidades geológicas pliopleistocénicas, indican que estas estructuras y el campo de esfuerzos asociado son recientes. En este sentido es muy interesante observar como las rosas referentes a los lineamientos detectados en depósitos cuaternarios presentan las mismas características que las otras rosas. Entonces es razonable pensar que el campo de esfuerzos que generó estos lineamientos (o por lo menos la mayoría de ellos), ha estado activo hasta el Cuaternario. Sin embargo, no es posible decir con seguridad que se trate también del mismo campo de esfuerzos activo actualmente.

Puede haber contradicción o falta de coherencia entre los resultados de la interpretación de los mecanismos focales de los sísmos por una parte y los datos mesoestructurales y fotolineamientos por otra, siendo que solo los primeros ofrecen realmente indicaciones sobre el campo de esfuerzos actual. En este sentido los mecanismos focales de los sísmos encontrados en la literatura no permiten tomar una posición unívoca sobre este problema. 


\section{AGRADECIMIENTOS}

Esta publicación ha sido posible gracias a la autorización de la Dirección General de Minería de la República Dominicana; en particular de los Ingenieros Iván Tavárez, Octavio José Lopez y Carmen Estevez.

Nuestros sinceros agradecimientos a aquellas personas que colaboraron a la realización del mapa de lineamientos y del respectivo informe durante el Proyecto SYSMIN: el Dott. Geol. Guido Mazzoleni, que detectó los lineamientos en las imágenes satelitares; el Ph.D. Andrea Zanchi por su ayudas y sugerencias en la definición del marco tectónico y del modelo cinemático; y el Dott. Geol. Bruno Floris por su ayuda en la elaboración de los datos.

\section{REFERENCIAS}

HOWELL, D., JONES, D. \& SCHERMER, E., 1985: Tectonostratigraphic terranos of the Circum-Pacific region. - En: HOWELL, D. (ed.): Tectonostratigraphic terranos of the Circum-Pacific region, - Houston, Texas, Earth Sciences Series 1: 3-30.

MANN, P., DRAPER, G. \& LEWIS, J.F., 1991: An overview of the geologic and tectonic development of Hispaniola. - En: MANN, P., DRAPER, G. \& LEWIS, J.F. (eds.): Geological and tectonic development of the North America-Caribbean plate boundary in Hispañiola.- Geol. Soc. America, Special Paper 262: 1-28.

MANN, P., PRENTICE, C.S., BURR, G., PEÑA, L.R. \& TAYLOR, F.W., 1998: Tectonic geomorphology and paleoseismology of the Septentrional fault system, Dominican Republic.- En: DOLAN, J. \& MANN, P. (eds.) Active strike slips and collisional tectonics of the northern caribbean Plate Boundary Zone. - Geol. Soc. America, Spec. Paper 326: 63-123. 